\title{
Can Micro-Credit Bring Development?
}

by

Christian Ahlin and Neville Jiang

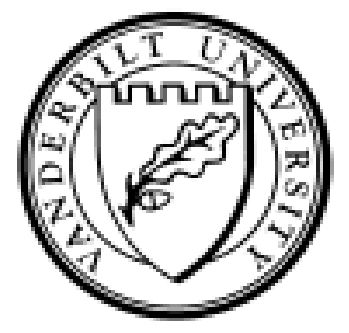

Working Paper No. 05-W19

July 2005

\section{DEPARTMENT OF ECONOMICS \\ VANDERBILT UNIVERSITY \\ NASHVILLE, TN 37235}

www.vanderbilt.edu/econ 


\title{
Can Micro-Credit Bring Development?
}

\author{
Christian Ahlin Neville Jiang*
}

July 2005

JEL No. D31, D82, O11

Keywords: Micro-credit; Occupational choice;

Long-run development; Poverty; Inequality

\begin{abstract}
We examine the long-run effects of micro-credit on development in an occupational choice model very similar to Banerjee and Newman (JPE, 1993). Micro-credit is modeled as a pure improvement in the credit market that opens up self-employment options to some agents who otherwise could only work for wages or subsist. Micro-credit can either raise or lower long-run GDP, since it can lower use of both subsistence and full-scale industrial technologies. It typically lowers long-run inequality and poverty, by making subsistence payoffs less widespread. A case exists, however, in which it both lowers output per capita and raises poverty in the long run. The key to microcredit's long-run effects is found to be the "graduation rate": the rate at which the self-employed build up enough wealth to start full-scale firms. We distinguish between two avenues for graduation: "winner" graduation (due to supernormal returns) and "saver" graduation (due to accumulation of normal returns). We find that "winner" graduation, however high its rate, cannot bring long-run development. In contrast, if the saving rate and normal returns in self-employment are jointly high enough, then micro-credit can bring an economy from stagnation to full development via "saver" graduation. The lasting effects of micro-credit may thus partially depend on simultaneous facilitation of micro-saving.
\end{abstract}

*Department of Economics, Vanderbilt University. We are grateful for encouragement and helpful comments to Francesco Caselli, James Foster, Mercedes Garcia-Escribano, Maitreesh Ghatak, Xavier Gine, Hyeok Jeong, Andrew Newman, Kenichi Ueda, Clara Vega, and seminar participants at Vanderbilt. All errors are our own. Email: c.ahlin@Vanderbilt.edu, nien-huei.jiang@Vanderbilt.edu. 


\section{Introduction}

Micro-credit has been hailed as "one of the most significant innovations in development policy of the past twenty-five years." ${ }^{1}$ This movement aims to extend small amounts of capital to poor borrowers throughout the world, most commonly intended for use in income-generating self-employment activities. In the process it has popularized creative and apparently ingenious lending techniques. For example, group lending pioneered by the Grameen Bank in Bangladesh and the Bank for Agriculture and Agricultural Cooperatives (BAAC) in Thailand, among others, has been shown theoretically to offer efficiency gains in contracting. ${ }^{2}$ Other aspects of micro-lending have also received attention, including its use of sequential loans and local information flows. ${ }^{3}$ Empirically, there is evidence that some of the mechanisms highlighted in theory are at work in practice. ${ }^{4}$ There is also some evidence for positive effects on household consumption and other variables from these programs. ${ }^{5}$

Virtually all of the research thus far focuses on partial effects of micro-credit, often in a static context. The literature seems relatively quiet about the longer-run issues involved micro-lending. On the empirical side, this may be readily explained by the relative youthfulness of the research agenda and the programs themselves. However, it does not seem too early to examine theoretically potential long-run effects of micro-credit. Taking a step in this direction is the goal of the current paper.

Specifically, we study the long-run effects of micro-credit on development, defined as output per capita, inequality, and poverty. We use the occupational choice setting of Banerjee and Newman (1993). The advantage of this model for our purposes is its distinction between self-employment and entrepreneurship. Entrepreneurial activities are assumed to

\footnotetext{
${ }^{1}$ Timothy Besley, quoted in Armendariz de Aghion and Morduch (2005). This book, Ghatak and Guinnane (1999), and Morduch (1999) provide broad introductions to the topic.

${ }^{2}$ See Stiglitz (1990), Banerjee et al. (1994), Besley and Coate (1995), and Ghatak (1999, 2000), among others.

${ }^{3}$ For example, see Armendariz de Aghion and Morduch (2000) and Rai and Sjöström (2004).

${ }^{4}$ See Wydick (1999), Karlan (2005), and Ahlin and Townsend (2004, 2005), among others.

${ }^{5}$ Armendariz de Aghion and Morduch (2005) provide a review of impact studies. In part, they argue that current knowledge of impacts could be significantly improved.
} 
require a relatively large scale of capital and employment of wage laborers, while engaging in self-employment requires capital and only one's own labor - a fitting description of many activities funded by micro-credit. ${ }^{6}$

We modify the model in two significant ways. First, we assume entrepreneurship is more efficient than self-employment. This creates a hierarchy of three technologies ranked by productivity and scale; in ascending order, they are subsistence, self-employment, and entrepreneurship. Second, we model micro-credit as the use of group lending to harness social penalties. This follows Besley and Coate (1995), and results in the borrower facing a higher cost of default. Assuming that social penalties are more acute for borrowers of lower wealth, as we do, micro-credit increases access to self-employment, but not entrepreneurship.

Thus micro-credit is modeled as a pure, if limited, improvement in the credit market. It opens up self-employment options to some agents who otherwise could only work for wages or subsist. Nevertheless, we find that micro-credit can raise or lower long-run output per capita. On the positive side, it lowers or eliminates use of the least-productive subsistence technology. On the negative side, it can diminish use of the most-productive entrepreneurial technology. This happens if micro-credit raises the wage and lowers entrepreneurial profits, causing unlucky entrepreneurs to fall out of the entrepreneurial class.

Micro-credit nearly always lowers poverty in our examples, defined as the number of people earning subsistence-level income. It does so either by raising the wage and/or by directly lifting some subsisters into self-employment. It also typically lowers inequality, by raising incomes of the poor and (potentially) lowering incomes at the top of the distribution by raising the wage paid by entrepreneurs. More specifically, it either raises income without sacrificing equality (raising the generalized Lorenz curve) or lowers inequality at the cost of lowering income (raising the Lorenz curve), under conditions we provide.

We uncover one exception to the above generalizations. When subnormal returns in

\footnotetext{
${ }^{6}$ For example, Grameen Bank founder Muhammad Yunus was reported to advocate frequently that "selfemployment should be preferred over wage-employment as a faster and more humane way to combat poverty," as paraphrased by Bornstein (1997, p. 331).
} 
entrepreneurship and self-employment are significantly more frequent than supernormal returns in self-employment, micro-credit can have a purely negative impact in the long run: more subsisters, fewer entrepreneurs, lower income, and greater poverty. This occurs even though initially income is raised and the number of subsisters is reduced.

We examine whether micro-credit can bring an underdeveloped economy to full development, defined as the steady state with only the most efficient technology in use, high wages, and no inequality. The key to micro-credit's long-run effects is the "graduation rate", that is, the rate at which the self-employed build up enough wealth to graduate into the entrepreneurial class.

There are several avenues for graduation. Micro-credit may be thought of as opening self-employment opportunities to many individuals and allowing the market to select for entrepreneurship those who excel. In this view, micro-credit essentially picks winners for graduation. Alternatively, graduation can be viewed as non-exceptional if an individual earning ordinary self-employment returns eventually saves enough to finance a full-scale business. Here, micro-credit facilitates graduation through saving. We distinguish between these two avenues for graduation: "winner" graduation and "saver" graduation. Specifically, the former avenue is open to those who earn relatively high returns in self-employment, while the latter comes from gradual accumulation of average self-employment returns.

Winner graduation alone cannot bring development. That is, regardless of the frequency of supernormal returns in self-employment (holding the mean fixed), the entrepreneurial class cannot be sufficiently built. The reason is that, as the entrepreneurial class grows to the key critical size, labor demand grows; consequently, more and more of the agents who could be self-employed choose wage labor instead and earn a certainty-equivalent wage. Thus, a vanishing segment of the middle class has the chance to earn supernormal returns. Though a high winner graduation rate cannot bring full development, it does result in higher long-run output. In fact, any mean-preserving spread that increases the frequency of supernormal and subnormal returns unambiguously raises long-run output. 
In contrast, if normal returns in self-employment and the saving rate are jointly high enough to allow for eventual graduation, then micro-credit can bring full development. Ultimately, it can move an economy from low output and subsistence wages to full development, vanishing in the long run. The key condition for this possibility is that the frequency and size of negative shocks in entrepreneurship are not too high to offset the rate of graduation into it.

Our paper has similarities with others in the literature. It borrows the basic framework from Banerjee and Newman (1993). Our focus on the effect of credit market improvements is different from theirs. Our results also differ due to our different productivity assumptions. We discuss briefly in section 4.1 what effect the introduction of micro-credit (as we model it) would have in their framework.

Matsuyama address similar issues in different models. Matsuyama (2005) shows that credit market improvements that increase access to non-frontier technologies may lower longrun efficiency, a phenomenon seen here. Matsuyama (2003) examines how the introduction of a moderately productive self-employment technology affects the set of potential steady states. He concludes that self-employment may raise or lower long-run income levels, similar to what we find here. These models differ from ours in significant ways. For example, they abstract from technological uncertainty, while uncertainty parameters figure prominently into the key conditions behind our analysis and results.

The policy conclusions we draw support a focus on 'micro-finance' rather than on 'microcredit' exclusively. That is, the model identifies a specific complementarity between enabling saving and micro-lending, since the saving rate must be sufficiently high for micro-credit to bring development. Of course, the average level of technology made available by microlending is also critical; if low, graduation may be impossible even with high savings rates. ${ }^{7}$

Finally, the model suggests that micro-credit institutions ought to be oriented toward

\footnotetext{
${ }^{7}$ Relatedly, Kaboski and Townsend (2005) find that village-level institutions that promote savings and that offer training and advice register the greatest positive impacts.
} 
graduating their borrowers toward larger undertakings, ${ }^{8}$ and even to different credit institutions; otherwise, their long-run impact may be limited or even harmful. A focus on graduation may make it hard to structure incentives for employees - to work themselves out of a job - and for borrowers - to repay loans when they are on the verge of graduating. Both of these incentive problems might be solved by information-sharing among credit institutions, or by micro-credit institutions aspiring not to remain exclusively micro-credit institutions forever.

Section 2 introduces the basic static elements of the model, with section 2.1 detailing the credit market and micro-credit. Section 3 introduces the dynamics. Section 4 presents the central examples and results: no graduation (section 4.1), winner graduation (section 4.2), and saver graduation (section 4.3). Section 5 discusses policy implications and concludes.

\section{The Model}

Our model borrows significantly from Banerjee and Newman (1993, hereafter BN); major departures will be noted. At any date $t$ there is a unit continuum of agents differing in wealth $w$. Let $G_{t}(w)$ be the fraction of agents with wealth less than $w$ at time $t$. Agents come to maturity at a random time distributed exponentially according to $\lambda$, independent of wealth. At the instant of maturity they engage in all economic activity. Each mature agent is then replaced by, and leaves a bequest to, an offspring. The offspring is then dormant until his random instant of maturity is realized. This process gives rise to a stationary population, with identical wealth distributions for the active population and the entire population. ${ }^{9}$ We set $\lambda \equiv 1$.

Agents have identical preferences over own consumption $C$ and bequest $B$ : $B^{s} C^{1-s}$. These preferences imply a fixed fraction of income $s$ being used as a bequest. They also

\footnotetext{
${ }^{8}$ This seems to support one of the well-known Grameen Bank 'Sixteen Decisions': "For higher income we shall collectively undertake bigger investments." See Bornstein (1997, p. 97).

${ }^{9}$ See BN (p. 278). As with them, our choice of overlapping generations in continuous time is to avoid jumps and overshooting.
} 
imply that indirect utility is linear in income, and thus agents are risk-neutral. ${ }^{10}$

We assume a small open economy facing world (gross) interest rate $\rho$. To restrict attention to finite wealth accumulation, we assume $s \rho<1$.

All agents are endowed with one unit of labor and choose the occupation in which to spend it. There are three production technologies available to produce the only final good: (1) a subsistence technology which requires no capital and one unit of labor; (2) a self-employment technology which requires $K^{S}$ units of the final good as an initial investment and one unit of labor; and (3) an entrepreneurial technology which requires a larger investment $K^{E}\left(>K^{S}\right)$ and $n \geq 1$ units of labor in addition to the entrepreneur's.

These technologies result in four occupations from which to choose: subsistence, selfemployment, entrepreneurship, and wage labor (for an entrepreneur). The subsistence technology produces $\underline{v}$ units of output. Thus an agent with endowment $w$ who subsists ends life with a net worth of $\underline{v}+\rho w$. Similarly, choosing to be a wage worker results in earned income of $v_{t}$, the market wage, and ending net worth of $v_{t}+\rho w$.

The remaining two occupations involve uncertainty. Self-employment produces a random rate of return $\widetilde{R}^{S}$, where this and other rates of return are taken net of the opportunity cost of capital $\rho$. For simplicity, $\widetilde{R}^{S}$ can take one of three values, high/supernormal $\left(R_{h}^{S}\right)$, medium/normal $\left(R_{m}^{S}\right)$, and low/subnormal $\left(R_{l}^{S}\right)$, with probabilities $\pi_{i}^{S}, i=h, m, l$, respectively. We assume that the expected net return, $\bar{R}^{S}$, equals the normal return, $R_{m}^{S}$. A self-employed agent with wealth $w$ ends with net worth of $\widetilde{R}^{S} K^{S}+\rho w$.

Entrepreneurship generates a random (net) rate of return $\widetilde{R}^{E}$. $\widetilde{R}^{E}$ can take two values, high $\left(R_{h}^{E}\right)$ and low $\left(R_{l}^{E}\right)$, with probabilities $\pi_{i}^{E}, i=h, l$, respectively. Let $\bar{R}^{E}$ denote the expected return. An entrepreneur with wealth $w$ ends with net worth of $\widetilde{R}^{E} K^{E}-n v_{t}+\rho w$, after paying the wage bill.

Let $\hat{v} \equiv \bar{R}^{S} K^{S}$ and $\bar{v} \equiv \bar{R}^{E} K^{E} /(n+1)$ be the output per unit of labor of the self-

\footnotetext{
${ }^{10}$ See BN. Unlike them, we assume labor is supplied inelastically, which is inconsequential to the results.
} 
employment and entrepreneurial technologies, respectively. We assume that

$$
\underline{v}<\hat{v}<\bar{v} .
$$

This assumption creates a hierarchy of technologies, with entrepreneurial production most efficient and subsistence least efficient. It embodies two key ideas. One is that capital intensity is a key to productivity (since subsistence is least productive). The other is that production organized within a firm is more efficient than production organized across autonomous individuals (since entrepreneurship is more productive than self-employment). This could be due to scale economies and/or specialization, for example.

This latter assumption is our key departure from BN. In their analysis, $K^{E}=n K^{S}$ and $\bar{R}^{E}=\bar{R}^{S}$; this implies that entrepreneurship is less productive than self-employment. ${ }^{11} \mathrm{We}$ have three reasons for using a different assumption. First, the concentration of production within relatively large firms in the rich countries makes it empirically plausible. Second, we aim to assess the long-run economic impact of micro-credit as an institution that moderately increases scale and capital-intensivity, but not to the ideal levels. ${ }^{12}$ It then may be useful to a stagnant economy as a stepping stone to fully efficient production, but it does not represent the ideal long-run solution. While some may dispute this, our third reason is that the results with the opposite assumption are relatively clear from the analysis already worked out in BN, making it straightforward to discuss how they would differ.

The first-best of this economy is achieved when exclusively entrepreneurial technology is used, that is, when there are $1 /(n+1)$ entrepreneurs and $n /(n+1)$ workers. A perfect credit market would give this outcome, but we assume there are imperfections.

\footnotetext{
${ }^{11}$ Entrepreneurship uses up one unit of labor on monitoring in their model.

${ }^{12}$ Assumptions will guarantee that micro-credit promotes self-employment but not entrepreneurship.
} 


\subsection{Credit market and micro-credit}

The credit market is competitive, leading to a (gross) interest rate of $r=\rho$ charged on all loans that involve no default risk. Following BN, we assume a borrower always can repay but may choose not to after production. Specifically, an agent who borrows $K$ can refuse to repay at the cost of facing a (non-monetary) punishment $F$ with probability $q$ and losing whatever collateral was pledged, $C$. Borrowers then face the choice of whether to default, saving principal and interest $r K$ but losing collateral $r C$ and facing expected penalty $q F$. If $r K>r C+q F$, i.e. $C<K-q F / r$, an agent will choose to default.

In equilibrium, lenders will demand sufficient collateral so that no default occurs. Thus $r=\rho$, and collateral $C \geq w^{*} \equiv K^{S}-q F / \rho$ is required from any agent seeking to become selfemployed and $C \geq w^{* *} \equiv K^{E}-q F / \rho$ from any agent seeking to become an entrepreneur. ${ }^{13}$ We assume the credit market imperfection is severe enough ( $q F$ small enough) so that $w^{*}>0$.

The credit market imperfection divides the population into three classes that differ in occupational possibilities. The wealthiest class, those with $w>w^{* *}$, can choose any occupation. We call them the "entrepreneurial class", or for convenience, the "upper class" and let $P_{t}^{U} \equiv 1-G_{t}\left(w^{* *}\right)$ denote their measure at date $t$. Similarly, the "lower class" with wealth $w<w^{*}$ can only subsist or work for wages; its measure is $P_{t}^{L} \equiv G_{t}\left(w^{*}\right)$. Finally, the residual "middle class" can choose any occupation but entrepreneurship; its measure is $P_{t}^{M} \equiv G_{t}\left(w^{* *}\right)-G_{t}\left(w^{*}\right)$.

Micro-credit is introduced in a simplistic but plausible way. We follow the strand of literature that views micro-credit as innovative use of joint liability contracts to enable more efficient lending to low-wealth borrowers. Specifically, as in Besley and Coate (1995, hereafter $\mathrm{BC})$, micro-credit makes default less attractive by harnessing social penalties.

Assume the lender pairs borrowers together in groups of two and makes each one responsible for the other's repayment. Specifically, if borrowers $i$ and $j$ are paired together and $j$

\footnotetext{
${ }^{13}$ In this model, an agent partially or fully self-financing is equivalent to an agent financing the full amount externally, since wealth is equally effective as collateral or productive capital. We can thus think of all agents as financing externally.
} 
defaults, $i$ faces penalty $F^{\prime}$ with probability $q^{\prime}$; and vice versa. This penalty is additional to any potential penalty incurred for his own default $(F)$. The additional penalty would be ineffective in encouraging repayment if not for the threat of social penalties - ostracism, withholding of informal aid or insurance, or the breaking of productive relationships - being imposed on a delinquent borrower. Thus, we follow BC in assuming a social penalty function. Let $\phi_{j}=\phi\left(q^{\prime} F^{\prime}, w_{j}\right)$ be the expected penalty imposed by $i$ on $j$ when $j$ owns wealth $w_{j}$, defaults, and causes $i$ to face additional expected penalty $q^{\prime} F^{\prime}$. It is plausible to assume (as do BC) that $\phi(\cdot, \cdot)$ increases in $q^{\prime} F^{\prime}$, the degree of harm to the partner caused by the default. More central is our assumption that $\phi(\cdot, \cdot)$ is decreasing in wealth $w$, i.e. that wealthier borrowers are less vulnerable (on average) to social penalties. We discuss this assumption below.

Repayment calculus changes with micro-credit. If a borrower of wealth $w$ chooses to default rather than repay, he saves principal and interest $\rho K$, loses collateral $\rho C$ and faces expected penalty $q F$, as before; in addition, there is the social penalty for defaulting, $\phi\left(q^{\prime} F^{\prime}, w\right)$. (He may also be penalized $q^{\prime} F^{\prime}$ by the lender for his partner's default, but this is independent of his own repayment decision.) Thus if $\rho K>\rho C+q F+\phi\left(q^{\prime} F^{\prime}, w\right)$, i.e. $C<K-q F / \rho-\phi\left(q^{\prime} F^{\prime}, w\right) / \rho$, default will occur.

Note that if $\phi\left(q^{\prime} F^{\prime}, w\right) \equiv \phi$, i.e. the social penalty is independent of the wealth level, then the introduction of micro-credit will reduce the wealth cutoffs $w^{*}$ and $w^{* *}$ by the same amount, $\phi / \rho$. On the other hand, if $\phi\left(q^{\prime} F^{\prime}, w\right)$ is decreasing in $w$, it is straightforward to show that the wealth cutoff $w^{*}$ will decline more than $w^{* *} ; 1^{14}$ higher-wealth agents are less affected because they face weaker social penalties. For concreteness, we make the extreme but simplifying assumption that $\phi\left(q^{\prime} F^{\prime}, w\right)=\phi$ if $w<K^{S}-q F / \rho$ and $\phi\left(q^{\prime} F^{\prime}, w\right)=0$ otherwise. This implies that micro-credit lowers $w^{*}$ without affecting $w^{* *}$.

How plausible is this assumption? We offer three justifications. First, empirically micro-

\footnotetext{
${ }^{14}$ Unless $\partial \phi / \partial w>-\rho$, there could be non-convexities in the sets of wealth levels that allow for selfemployment and entrepreneurship, respectively. Single cutoff wealth levels would then be insufficient to describe the sets.
} 
lending is almost exclusively targeted at low-wealth borrowers, often engaged in small-scale self-employment activities. ${ }^{15}$ Our assumption matches this empirical regularity. It is also plausible that dependence on informal insurance networks, which can be the basis for informal penalties, ${ }^{16}$ declines with wealth. Second, the assumption can be viewed definitionally. Essentially, we are defining micro-credit as a credit market improvement that expands access to small-scale self-employment technology, but not (directly) to large-scale industrial technology. Even if the underlying mechanism we use is debatable, ${ }^{17}$ the resulting definition seems unexceptionable (especially given the term itself, "micro"-credit). To the extent it is not, our third reason is that the effect of this assumption will be relatively straightforward to see in our final analysis.

In summary, micro-credit is modeled as a pure, if limited, improvement in the credit market. It has the immediate effect of growing the middle class $P_{t}^{M}$ at the expense of the lower class $P_{t}^{L}$, without changing the upper class $P_{t}^{U}$.

\subsection{Labor market equilibrium}

Occupational choices depend on the equilibrium wage. The wage in turn depends on the wealth distribution as summarized through $P_{t}^{U}, P_{t}^{M}$, and $P_{t}^{L}$, since these determine labor supply and demand; these are graphed in Figure 1.

Labor demand can only arise from the upper class, who are able to become entrepreneurs. Given assumption A1, it is straightforward to show that entrepreneurship gives the best payoff as long as $v_{t}<\bar{v}$. This critical wage $\bar{v}$ equates the wage labor payoff, $v_{t}$, with the

\footnotetext{
${ }^{15}$ The assumption that the self-employed hire no workers does not appear to be essential. We conjecture that the results of this paper would not change qualitatively if the self-employed hired workers. The key results depend on greater productivity and capital scale in entrepreneurship.

${ }^{16}$ Paal and Wiseman (2005) model loan repayment incentives in the context of informal insurance networks.

${ }^{17}$ There are alternative routes to the same definition. One could assume the social penalty is occupationspecific, positive for self-employment and zero for entrepreneurship. This would be justified if the entrepreneurial technology had to be employed in an anonymous or high-mobility urban context, while the self-employment technology could be operated in a village, with tight social networks. Banerjee and Newman (1998) tell a related story. Madajewicz (2005) shows in a hidden action environment how joint liability loans may not be optimal for higher-wealth borrowers since the increased risk dominates the benefit of increased monitoring incentives. Finally, one could simply assume that micro-credit is targeted at borrowers below a certain wealth level.
} 
expected entrepreneurial payoff, $\bar{R}^{E} K^{E}-n v_{t}$. If $v_{t}>\bar{v}$, wage labor gives the highest payoff. Thus, since each entrepreneur hires $n$ workers, total demand will be $n P_{t}^{U}$ if $v_{t}<\bar{v}$; 0 if $v_{t}>\bar{v}$; and any amount in $\left[0, n P_{t}^{U}\right]$ if $v_{t}=\bar{v}$, since the upper class are then indifferent between wage labor and entrepreneurship.

Turning to labor supply, note that there are three levels for the wage that put wage labor on a par with the three respective occupations: $\underline{v}$ for subsistence, $\bar{v}$ for entrepreneurship, and $\hat{v}$ for self-employment. Given the occupational restrictions placed by the credit market, labor supply is then zero when $v_{t}<\underline{v} ; P_{t}^{L}$ when $\underline{v}<v_{t}<\hat{v} ; P_{t}^{L}+P_{t}^{M}$ when $\hat{v}<v_{t}<\bar{v}$; and 1 when $\bar{v}<v_{t}$. If $v_{t}$ equals $\underline{v}, \hat{v}$, or $\bar{v}$, a mass of agents is indifferent between labor and some other occupation, and labor supply can take any value between its limits from below and above.

Combining supply and demand leads to one of the following three equilibrium wages. ${ }^{18}$

- If $n P_{t}^{U}<P_{t}^{L}$, the equilibrium wage rate is $v_{t}=\underline{v}$.

- If $P_{t}^{L}<n P_{t}^{U}<P_{t}^{L}+P_{t}^{M}$, the equilibrium wage rate is $v_{t}=\hat{v}$.

- If $P_{t}^{L}+P_{t}^{M}<n P_{t}^{U}$, that is, $P_{t}^{U}>1 /(1+n)$, the equilibrium wage rate is $v_{t}=\bar{v}$.

In the first case, the pool of potential entrepreneurs is too small relative to the population whose only options are wage labor or subsistence. The wage is bid down to subsistence level. All upper-class agents take advantage of the low wages to become entrepreneurs; all middleclass agents choose self-employment; and some of the lower class work in firms $\left(n P_{t}^{U}\right)$ while the rest subsist $\left(P_{t}^{L}-n P_{t}^{U}\right)$.

In the second case, there are enough potential entrepreneurs to need some middle-class workers, so they pay $\hat{v}$. All upper-class agents become entrepreneurs, all lower-class and some middle-class agents become workers, and the rest of the middle-class $\left(1-(n+1) P_{t}^{U}\right)$ become self-employed.

\footnotetext{
${ }^{18} \mathrm{BN}$ are left with two potential wages rather than three due to their assumption that self-employment is more productive than entrepreneurship.
} 
In the third case, the potential entrepreneurial pool is so large that it needs to attract some of its own members to work. The equilibrium wage makes working in a firm as attractive as running one. All lower- and middle-class agents, and some upper-class agents, become workers and receive the same labor income ${ }^{19}$ as entrepreneurs (in expected value). Since everyone in this economy is working in a firm with the entrepreneurial technology, the highest aggregate output is achieved; and the high wages guarantee perfect equality in (expected) income.

The wealth distribution thus determines the current wage rate, which in turn determines occupations, incomes, and the future wealth distribution. ${ }^{20}$ We turn now to these wealth dynamics.

\section{Dynamics}

In section 3.1, we present the family wealth dynamics under each of the three potential equilibrium wages discussed above. Section 3.2 considers aggregate wealth dynamics.

\subsection{Family dynamics}

An agent passes a fraction $s$ of his ending net worth to his offspring. Let $V\left(v_{t}, w\right)$ be the occupation-specific income earned by an agent of wealth $w$ who comes to maturity when the wage is $v_{t}$; these values are readily calculated from the discussion of the three cases in section 2.2. The bequest his offspring receives, i.e. his offspring's wealth, is then $w^{\prime}=s\left[V\left(v_{t}, w\right)+\rho w\right]$.

Recall from section 2.2 that $P_{t}^{U}$ and $P_{t}^{L}$ are the only features of the wealth distribution needed to calculate the wage $v_{t}$ at any time $t .{ }^{21}$ However, generally the entire wealth distri-

\footnotetext{
${ }^{19}$ Throughout the paper, we use "labor income" and "income" as shorthand for the occupation-specific component of income. That is, it excludes the interest income $\rho w$.

${ }^{20}$ The cases where $n P_{t}^{U}$ exactly equals either $P_{t}^{L}$ or $P_{t}^{L}+P_{t}^{M}$ can see any of a range of wages. We assume the highest possible wage prevails in these cases.

${ }^{21} P_{t}^{M}$ is calculated from these as the remainder from one.
} 
bution is needed in order to track the evolution of $P_{t}^{U}$ and $P_{t}^{L}$ over time. For tractability, we follow BN and restrict analysis to cases where the wealth class of any agent, along with the resolution of uncertainty, is sufficient to determine the wealth class of his offspring. This dramatically reduces the state-space, to the two-dimensional simplex $\left(P_{t}^{L}, P_{t}^{U}\right)$.

One set of parameter values allowing for this dimensional reduction is displayed graphically in Figure 2. There are three panels, since family transitions will depend on the wage rate prevailing at the time of activity. The first panel corresponds to $v_{t}=\underline{v}$. At this wage the lower class work or subsist to earn $\underline{v}$. The graph depicts them as stuck in the lower class: given the saving and interest rates, they can never accumulate enough to finance selfemployment. $^{22}$ The middle class are all self-employed. The graph depicts them remaining in the middle class if they earn normal returns, graduating to the upper class if they receive supernormal returns, and falling into the lower class if they receive subnormal returns. Finally, the upper class work as entrepreneurs. The graph depicts them always earning enough to stay in the upper class: even if unlucky, the wage bill is low enough to keep them wealthy.

These parameters guarantee that in order to know an agent's offspring's class, it is sufficient to know the agent's current class (along with the resolution of uncertainty, in some cases). Beyond this, how plausible are the assumptions embodied in the first panel? It is common in these kinds of models to assume that subsistence technology leads to a poverty trap, i.e. does not provide an exit from low wealth through accumulation. Our assumptions about self-employment are flexible in allowing transit to any class; the restriction is that the normal (mean) return guarantees staying in the middle class. This seems plausible. It restricts "graduation" from the middle to the upper class to those earning supernormal returns, i.e. the "winners". We use an alternative assumption, that accumulation of normal self-employment returns enables graduation, in section 4.3.

The second panel applies to $v=\hat{v}$ and differs from the first in two regards. First, the lower class now earn wages equal to the expected payoff from self-employment; we assume

\footnotetext{
${ }^{22}$ The condition for this is $s\left(\underline{v}+\rho w^{*}\right)<w^{*}$, that is, $s \underline{v} /(1-s \rho)<w^{*}$.
} 
this is sufficient to transit to the middle class. Second, unlucky entrepreneurs face a high enough wage bill that they drop to the middle class. This plausible assumption drives some of our later results, but not key propositions 1 and 2. The middle class payoffs are unchanged since they continue to choose self-employment, or else work for similar wages.

The third panel applies to $v=\bar{v}$. There, wages are so high that both low- and middle-class families transit to the upper class. The down side is that unlucky entrepreneurs now transit to the lower class after paying the high wage bill. Our results would be equivalent if unlucky entrepreneurs transited to the middle class - everyone earns the same high (expected) income regardless, and the dynamics will guarantee that the wage remains high if it ever gets high.

\subsection{Aggregate dynamics}

Given the family wealth evolution described in the previous section and Figure 2, we can accomplish our ultimate objective: tracing the economy-wide wealth and income distributions. Each of the panels in Figure 2 leads to a pair of first-order differential equations in $P_{t}^{L}$ and $P_{t}^{U}$. For example, when $v_{t}=\underline{v}$

$$
\begin{aligned}
& \dot{P}_{t}^{U}=\pi_{h}^{S}\left(1-P_{t}^{L}-P_{t}^{U}\right) \\
& \dot{P}_{t}^{L}=\pi_{l}^{S}\left(1-P_{t}^{L}-P_{t}^{U}\right) .
\end{aligned}
$$

These equations reflect the fact that when $v_{t}=\underline{v}$ the only class mobility comes from the middle class, ${ }^{23}$ all of whom are self-employed. A fraction $\pi_{h}^{S}$ of the middle class who are active at date $t$ are winners and graduate to the upper class, causing $P_{t}^{U}$ to grow. Similarly, a fraction $\pi_{l}^{S}$ are unlucky and drop to the lower class, causing $P_{t}^{L}$ to grow.

When $v_{t}=\hat{v}$

$$
\begin{aligned}
& \dot{P}_{t}^{U}=\pi_{h}^{S}\left[1-(n+1) P_{t}^{U}\right]-\pi_{l}^{E} P_{t}^{U} \\
& \dot{P}_{t}^{L}=\pi_{l}^{S}\left[1-(n+1) P_{t}^{U}\right]-P_{t}^{L}
\end{aligned}
$$

\footnotetext{
${ }^{23}$ Again, the middle class is fully determined by $P_{t}^{L}$ and $P_{t}^{U}: P_{t}^{M}=1-P_{t}^{L}-P_{t}^{U}$.
} 
Again, the middle class provides mobility, but only those who are self-employed. Recall that the middle class divides itself between wage labor and self-employment when $v_{t}=\hat{v}$. In fact, the entire population is running in or working in a firm except the self-employed middle class. Since there are $P_{t}^{U}$ firms, the measure of self-employed must be $1-(n+1) P_{t}^{U}$. Mobility also comes from active lower class agents; at this wage they immediately move up to the middle class (hence the $-P_{t}^{L}$ term in $\dot{P}_{t}^{L}$ ). Active upper class agents whose firms perform poorly now drop out of the upper class (hence the $-\pi_{l}^{E} P_{t}^{U}$ term in $\dot{P}_{t}^{U}$ ).

When $v_{t}=\bar{v}$,

$$
\begin{aligned}
& \dot{P}_{t}^{U}=\left(1-P_{t}^{U}\right)-\frac{\pi_{l}^{E}}{n+1} \\
& \dot{P}_{t}^{L}=-P_{t}^{L}+\frac{\pi_{l}^{E}}{n+1} .
\end{aligned}
$$

The first term in $\dot{P}_{t}^{U}$ is because everyone not in the upper class transits there $\left(1-P_{t}^{U}\right)$, due to the high wages. The second term reflects the fraction of unlucky entrepreneurs who drop to the lower class. The maximum number of entrepreneurs in the economy is $1 /(n+1)$; this is also the actual number whenever the wage is this high. The first term in $\dot{P}_{t}^{L}$ is because the active lower class agents transit out of it; the second term captures the unlucky entrepreneurs.

The economy can be described at any time $t$ by a point on the two-dimensional simplex $\left(P_{t}^{L}, P_{t}^{U}\right)$; see Figure 3. This triangle is subdivided into three "regions" corresponding to the three equilibrium wages (see section 2.2). Points in the upper triangle where $P_{t}^{U}>1 /(n+1)$ involve the high wage $v_{t}=\bar{v}$. Points in the lower right triangle where $P_{t}^{U}<P_{t}^{L} / n$ involve the low wage $v_{t}=\underline{v}$. The remaining triangle involves the medium wage, $v_{t}=\hat{v}$. The economy's initial location thus determines which of the dynamics (equations 1-3) apply at the outset and whether the economy may ultimately progress to higher wages and greater efficiency. 


\section{Micro-Credit and long-run development}

We illustrate the possibilities opened up by micro-credit through several examples. Our strategy is to compare the long-run outcomes of two initially identical economies, only one of which experiences the introduction of micro-credit.

\subsection{Dynamics with no graduation}

Consider the simple case in which uncertainty in self-employment returns is eliminated: $\pi_{h}^{S}, \pi_{l}^{S}=0$. Here there is no way to graduate upward from the middle class.

Figure 3 shows the evolution of the wealth distribution. We see from equations 1 that $\dot{P}_{t}^{U}=\dot{P}_{t}^{L}=0$ in the $\underline{v}$-region. ${ }^{24}$ Each class is absorbing, so that a wealth distribution in this region stagnates at the same location forever; see point $\underline{S S}$ in Figure 3 . A wealth distribution in the $\hat{v}$-region, however, converges to the origin (point $\widehat{S S}$ ), since both $\dot{P}_{t}^{U}$ and $\dot{P}_{t}^{L}$ are negative (equations 2). ${ }^{25}$ The $\hat{v}$-region thus involves shrinking upper and lower classes (the latter due to high wages, the former due to bad shocks) and an absorbing middle class; in the end, all are self-employed. In the $\bar{v}$-region, any distribution converges to point $\overline{S S}$ defined as $\left(P \frac{L}{S S}, P \frac{U}{S S}\right)=\left(\frac{\pi_{l}^{E}}{n+1}, 1-\frac{\pi_{l}^{E}}{n+1}\right) \cdot{ }^{26}$ All agents are employing the most efficient technology and have the same expected income. Finally, notice that each region of the simplex is self-contained, that is, there are no paths from one wage region to another.

We can compare the (labor) income distributions of these possible long-run economies in terms of both average level, inequality, and poverty. To facilitate discussion about poverty, we assume the poverty line $p$ satisfies

$$
\underline{v}<p<\hat{v}
$$

As mentioned, economy $\overline{S S}$ involves use of only the most efficient technology; further,

\footnotetext{
${ }^{24}$ Of course, $\dot{P}_{t}^{M}=-\left(\dot{P}_{t}^{U}+\dot{P}_{t}^{L}\right)$ is also zero here.

${ }^{25}$ One can show that the trajectory stays within the $\hat{v}$-region.

${ }^{26}$ One can show that the trajectory stays within the $\bar{v}$-region.
} 
everyone earns $\bar{v}$ (in expected value), so there is no poverty or inequality. We refer to this ideal outcome as synonymous with "development". Economy $\widehat{S S}$ also has perfect equality and no poverty since everyone is self-employed. Average income is of course lower, though, at $\hat{v}$. Finally, economy $\underline{S S}$ clearly has higher poverty and inequality than the others, as the lower class earn $\underline{v}$, the middle class earn $\hat{v}$, and the upper class earn $\bar{R}^{E} K^{E}-n \underline{v}$. Average income is a weighted average of the three technologies' productivities. It is thus clearly lower than at $\overline{S S}$, but can be higher than at $\widehat{S S}$, since it involves both more entrepreneurship and more subsistence. In particular, there is a critical line from the origin, with slope less than $1 / n$ and therefore lying in the $\underline{v}$-region. If $P_{0}^{U} / P_{0}^{L}$ is high enough so that $\underline{S S}$ lies above this line, then $\underline{S S}$ has higher income than $\widehat{S S}$; and vice versa. ${ }^{27}$

Now imagine two economies at $\underline{S S}$ and the introduction of micro-credit in one. Can this financial development bring the economy to development? Recall from section 2.1 that the introduction of micro-credit is equivalent to a decline in $P_{t}^{L}$ mirrored by a rise in $P_{t}^{M}$, with $P_{t}^{U}$ unchanged. In Figure 3 this would be represented by a leftward shift from point $\underline{S S}$. There are two qualitative cases to consider. First, micro-credit may impact few enough people that the economy remains in the $\underline{v}$-region (pictured as the shift to $\underline{S S^{\prime}}$ ). The only change in the economy is that the agents impacted by micro-credit move from subsistence or wage labor to self-employment. Clearly, average income rises and poverty falls. The new and old Lorenz curves cross, though, so inequality is less clear; but the new generalized Lorenz curve dominates the old one. ${ }^{28}$ Second, micro-credit may impact enough people, that is, improve enough agents' productive options, to raise the wage to $\hat{v}$ (pictured as the shift to $\left.\underline{S S}^{\prime \prime}\right)$. As analyzed above, this economy will converge to steady state $\widehat{S S}$, getting rid of inequality and poverty, but potentially lowering total output if the initial point $\underline{S S}$ was high enough. ${ }^{29}$

\footnotetext{
${ }^{27}$ Income at $\underline{S S}$ can be written as $(n+1) P_{0}^{U} \cdot \bar{v}+P_{0}^{M} \cdot \widehat{v}+\left(P_{0}^{L}-n P_{0}^{U}\right) \cdot \underline{v}$. The slope of the critical line in the $\underline{v}$-region is then calculated as $1 /\left[n\left(1+\frac{\bar{v}-\hat{v}}{\hat{v}-\underline{v}} \frac{n+1}{n}\right)\right]$.

${ }^{28}$ The generalized Lorenz curve is the Lorenz curve multiplied by the mean income. Generalized Lorenz dominance is the extension of Lorenz dominance to generalized Lorenz curves.

${ }^{29}$ Note that even if $\pi_{l}^{E}=0$, so that the higher wages do not hurt entrepreneurs' class transitions, development cannot be reached. In this case, the steady state will be horizontally to the left at $\left(P_{0}^{U}, 0\right)$. However,
} 
In summary, the introduction of micro-credit lowers poverty and inequality (with exceptions under Lorenz dominance, but not generalized Lorenz dominance, if it fails to raise the wage). Micro-credit may or may not raise total income, however, since it can reduce the use of the most productive, entrepreneurial technology if it is widespread enough. In any case, micro-credit cannot bring full development when $\pi_{l}^{S}=\pi_{h}^{S}=0 .{ }^{30}$

\subsection{Dynamics with winner graduation}

The development prospects of micro-credit may be enhanced if it provides a substantial possibility of graduating from self-employment to entrepreneurship. Here we study the dynamics when there is uncertainty in self-employment returns. Specifically, with probability $\pi_{h}^{S}>0$ an agent experiences supernormal returns allowing his offspring to graduate to entrepreneurship, while with probability $\pi_{l}^{S}>0$ an agent experiences subnormal returns and puts his offspring in the lower class.

Figure 4 shows the evolution of the wealth distribution. The $\bar{v}$-region sees the same dynamics (convergence to $\overline{S S}$ ) as in section 4.1, since $\pi_{h}^{S}$ and $\pi_{l}^{S}$ do not figure into equations 3 . Dynamics in the $\underline{v}$-region now reflect a shrinking middle class: there remains no mobility out of the upper and lower classes, but a constant flow into each from the middle class. The economy moves upward and to the right along a linear trajectory whose steepness depends on the relative rates of graduating upward and dropping into poverty out of self-employment.

output will be higher and inequality and poverty lower than before micro-credit.

${ }^{30}$ It can now be made clear how the assumption that entrepreneurial technology is the most productive affects our results. If instead self-employment is most productive, as in BN, then micro-credit immediately promotes the best technology and can bring full development if sufficiently widespread. This can be seen by a leftward shift (as described above) in Figure 3 of BN.

The impact of our assumption that informal penalties are zero above some wealth level is also clear. Relaxing this would mean that an economy moved leftward and upward after the introduction of microcredit, since the entrepreneurial class would grow just as the lower class would shrink. Micro-credit could then effect development if the immediate upward movement it induced was sufficient to raise the wage to $\bar{v}$ (i.e. raise $P_{0}^{U}$ to $1 /(n+1)$ ). This highlights the interpretation of our results: they hold when micro-credit is an institution that promotes access to more productive, but not the most productive, technology. 
Specifically, equations 1 give its slope $\dot{P}_{t}^{U} / \dot{P}_{t}^{L}$ as

$$
a \equiv \pi_{h}^{S} / \pi_{l}^{S}
$$

\subsubsection{Dynamics with a large}

We consider first the most promising case, where $a$ is large. Specifically, assume $a>1 / n$. This implies that the trajectory within the $\underline{v}$-region is steeper than the region's upper boundary, $P_{t}^{U}=P_{t}^{L} / n$. Some initial distributions will therefore hit and cross the upper boundary into the $\hat{v}$-region as the growth of the upper class raises wages. These starting points have relatively high $P_{0}^{U}$ compared to $P_{0}^{L}$; they correspond to the non-shaded area of the $\underline{v}$-region in Figure 4. ${ }^{31}$ The remaining initial distributions, in the shaded area, will converge to points on the upper right leg of the $\underline{v}$-region where $P_{t}^{U}+P_{t}^{L}=1$; one example is denoted by $\underline{S S} .{ }^{32}$

It can be verified that all distributions in the $\hat{v}$-region will converge to

$$
\left(P_{\widehat{S S}}^{L}, P_{\widehat{S S}}^{U}\right)=\left(\frac{\pi_{l}^{E} / a}{n+1+\frac{\pi_{l}^{E}}{\pi_{h}^{S}}}, \frac{1}{n+1+\frac{\pi_{l}^{E}}{\pi_{h}^{S}}}\right)
$$

Figure 4 depicts the phase diagram and steady state denoted by $\widehat{S S}$.

Can micro-credit bring an underdeveloped (low- or mid-wage) economy to full development? No. Figure 4 makes clear that a leftward shift of any economy may eventually bring the economy to the mid-wage steady state $\widehat{S S}$, but it cannot bring it to the high-wage steady state $\overline{S S}$. This is also clear from equation $4: P_{\widehat{S S}}^{U}$ is less than the critical value of $1 /(n+1)$ no matter what the value of $\pi_{h}^{S}$. Technically, even if $\pi_{l}^{E}=0$ so that $P_{\widehat{S S}}^{U}=1 /(n+1)$ the economy will not reach $\overline{S S}$; $P_{t}^{U}$ will get arbitrarily close to $1 /(n+1)$ but can be shown always to be smaller at any finite $t$.

Proposition 1. Under assumption A1 and family dynamics as displayed in Figure 2, micro-

\footnotetext{
${ }^{31}$ This area satisfies $P_{0}^{U}>a P_{0}^{L}-\frac{a n-1}{n+1}$.

${ }^{32}$ Specifically, $\left(P_{0}^{L}, P_{0}^{U}\right)$ will converge to $\left(P_{\underline{S S}}^{L}, P_{\underline{S S}}^{U}\right)=\left(\frac{1+a P_{0}^{L}-P_{0}^{U}}{a+1}, \frac{a-a P_{0}^{L}+P_{0}^{U}}{a+1}\right)$, still in the $\underline{v}$-region.
} 
credit cannot bring an underdeveloped (low-or mid-wage) economy to full development.

Proof: see Appendix.

This result is due to the fact that only middle class agents that are not needed in a firm are self-employed when $v=\hat{v}$. If $P_{t}^{U}$ were to approach the critical value $1 /(n+1)$ (for example, if $\pi_{l}^{E}=0$ ), labor demand would grow, mirrored by the number of self-employed approaching zero. This eliminates the necessary upward mobility because only the self-employed middle class can achieve the supernormal returns needed for graduation; wage workers earn the certainty-equivalent. However high the winner graduation rate $\left(\pi_{h}^{S}<1\right)$ is, development will not be achieved due to the vanishing incidence of self-employment.

While not a panacea, micro-credit can have positive long-run effects. ${ }^{33}$ Economies starting in the shaded area of the $\underline{v}$-region in Figure 4 will have their long-run outcomes altered. (All other economies have the same long-run destiny with or without micro-credit.) As in section 4.1, there are two qualitative cases to consider. First, micro-credit may impact few enough people that the economy remains in the shaded area of the $\underline{v}$-region (pictured as the shift from $I$ to $I^{\prime}$ ). Some of the agents lifted to self-employment eventually become entrepreneurs, leaving the long-run economy with more entrepreneurs and fewer subsisters $\left(\underline{S} S^{\prime}\right.$ instead of $\left.\underline{S S}\right)$. Clearly, average income rises and poverty falls. The new and old Lorenz curves cross, but the new generalized Lorenz curve dominates the old.

Second, micro-credit may impact enough people to move the economy out of the shaded area (the shift from $I$ to $I^{\prime \prime}$ ) and thus ultimately to $\widehat{S S}$. How does this steady state compare to the one that would have obtained $(\underline{S S})$ ? The poverty comparison is straightforward. Economy $\widehat{S S}$ has no poverty since the wage is at $\hat{v}$. Economy $\underline{S S}$ does have poverty due to the low wage and positive mass of lower class citizens.

The output comparison can go either way. Average output at $\underline{S S}$ is just a convex combination of the entrepreneurial and subsistence productivities, since these are the only

\footnotetext{
${ }^{33}$ In fact, development is unreachable via favorable initial conditions alone, for an economy that begins underdeveloped. Micro-credit cannot change this, but financial market improvements that open access to larger-scale entrepreneurship can.
} 
technologies in operation; similarly, average output at $\widehat{S S}$ is a convex combination of the entrepreneurial and self-employment productivities:

$$
\begin{aligned}
& Y_{\widehat{S S}}=\bar{v} \cdot P_{\widehat{S S}}^{U}(n+1)+\hat{v} \cdot\left[1-P_{\widehat{S S}}^{U}(n+1)\right] \\
& Y_{\underline{S S}}=\bar{v} \cdot P_{\underline{S S}}^{U}(n+1)+\underline{v} \cdot\left[1-P_{\underline{S S}}^{U}(n+1)\right] .
\end{aligned}
$$

Both equations reflect the fact that the total population working in firms is $P_{t}^{U}(n+1)$. $Y_{\underline{S S}}$ can be arbitrarily close to $\bar{v}$, since $P_{\underline{S S}}^{U}$ can be arbitrarily close to $1 /(n+1)$, the top point in the $\underline{v}$-region, depending on initial conditions. By contrast, $Y_{\widehat{S S}}$ is fixed strictly below $\bar{v}$ since $P_{\widehat{S S}}^{U}$ is strictly less than $1 /(n+1)$, regardless of initial conditions (see equation 4$)$. Thus there is a range of steady states $\underline{S S}$ in the $\underline{v}$-region that involve higher production than $\widehat{S S} \cdot{ }^{34}$ The intuition is the same as that in section 4.1. On the positive side, micro-credit reduces use of subsistence technology in favor of self-employment technology; on the negative side, it raises the wage and can lower use of the entrepreneurial technology in the long run.

Both steady states involve inequality, and inequality comparisons can seem ambiguous. There are low-wage steady states $\underline{S S}$ that are arbitrarily close to perfect equality. These involve a negligible upper class $P_{\underline{S S}}^{U}$ : average income is near $\underline{v}$ and most people earn $\underline{v}$. On the other hand, it is straightforward to show that if $P_{\underline{S S}}^{U}=P_{\widehat{S S}}^{U}$, the mid-wage economy $\widehat{S S}$ Lorenz dominates the low-wage economy $\underline{S S}$. However, the ambiguity is itself a bit misleading, in the following sense. When $\widehat{S S}$ has higher income than $\underline{S S}, \widehat{S S}$ also generalized-Lorenz dominates $\underline{S S}$ (though it may be Lorenz dominated). When $\widehat{S S}$ has lower income than $\underline{S S}$, the generalized Lorenz curves cross; but $\widehat{S S}$ Lorenz dominates $\underline{S S}$ if

$$
\frac{\hat{v}}{\bar{v}}\left(1+\frac{\hat{v}-\underline{v}}{\bar{v}-\hat{v}}\right) \geq \frac{n+1}{n}
$$

\footnotetext{
${ }^{34}$ It is clear from the above equations that these steady states must involve $P_{\underline{S S}}^{U}>P_{\widehat{S S}}^{U}$. Specifically, $Y_{\underline{S S}}>Y_{\widehat{S S}}$ iff $P_{\underline{S S}}^{U}>Q$, where$$
Q \equiv \frac{1}{n+1}\left[\frac{P_{\widehat{S S}}^{U}(n+1)+\frac{\hat{v}-\underline{v}}{\bar{v}-\hat{v}}}{1+\frac{\hat{v}-\underline{v}}{\bar{v}-\hat{v}}}\right]<\frac{1}{n+1}
$$ 
In summary, ${ }^{35}$ either $\widehat{S S}$ achieves higher income without sacrificing equality, or it achieves lower income but a more equal distribution (under condition A3).

We finally note that risk-taking in self-employment gives long-run benefits to economies transiting toward $\widehat{S S}$. Consider a mean-preserving spread in returns that raises $\pi_{h}^{S}$ and $\pi_{l}^{S}$ while holding fixed their ratio $a$ as well as $R_{h}^{S}, R_{m}^{S}$, and $R_{l}^{S}$. This raises $P_{\widehat{S S}}^{U}$ (see equation 4), which unambiguously raises output (see equation 5). The resulting income distribution generalized-Lorenz dominates the original. This result suggests that encouraging risk-taking in self-employment activities rather than failsafe approaches (which prop up repayment rates) may improve long-run outcomes. ${ }^{36}$

Micro-credit cannot bring full development if it relies only on winner graduation for mobility into the entrepreneurial class. It can, however, have a positive impact on total output, income disparity, or both. We next show that micro-credit can have a purely negative impact when $a$ is small.

\subsubsection{Dynamics with a small}

The case where $a<1 / n$ subdivides into two subcases. First, assume $\pi_{l}^{E} / n<a<1 / n$. This is very similar to the case where $a>1 / n$. One difference is that trajectories in the $\underline{v}$-region have slopes less than $1 / n$ and thus never exit the region. This implies there is no possibility to raise the wage from $\underline{v}$ to $\hat{v}$ without micro-credit. Graphically, the whole $\underline{v}$-region would be shaded in Figure 4. A second difference is that it is possible to exit the $\hat{v}$-region (from its lower left quadrant only) into the $\underline{v}$-region. For example, consider a point near the origin. The slope $\dot{P}_{t}^{U} / \dot{P}_{t}^{L}$ is approximately $a$, which is less than the slope of the boundary, $1 / n$. Thus there are cases in which micro-credit raises the wage only temporarily; these all involve long-run improvements, however, since the upper class to lower class ratio is better after this temporary phase. Apart from these differences, all previous results apply.

\footnotetext{
${ }^{35}$ Even without condition A3, $\widehat{S S}$ is never Lorenz dominated by $\underline{S S}$ when $Y_{\underline{S S}}>Y_{\widehat{S S}}$; but there may be steady states $\underline{S S}$ (with high enough $P_{\underline{S S}}^{U}$ ) whose Lorenz curves cross that of $\widehat{S S}$.

${ }^{36} \mathrm{~A}$ more comprehensive approach would weigh this against risk aversion, from which our model abstracts. Also, our analysis thus far assumes no possibility of saver graduation.
} 
The more interesting subcase is where $a<\pi_{l}^{E} / n$. In this case, there is no steady state in the $\hat{v}$-region; all economies there eventually drop into the $\underline{v}$-region, as is evident from Figure 5. This happens because the rate of graduation from middle to upper class, $\pi_{h}^{S}$, is so low relative to the rate of falling out of the upper class, $\pi_{l}^{E}$, that $P_{t}^{U}$ is falling even when very low. This allows the middle class to get so big relative to the lower class, while the upper class is still declining, that downward mobility out of the middle class begins to dominate upward mobility into it from the lower class. The lower class begins to rebound, and eventually, the upper class decline and lower class resurgence is sufficient to lower the wage to $\underline{v}$. At this point, $\underline{v}$-region dynamics take over and the steady state is on the upper right leg of the $\underline{v}$-region.

Under these parameters, micro-credit can make an economy unambiguously worse off in the long run. It can do so, paradoxically, only if it is widespread enough to effect a transition to the mid-wage $\hat{v} \cdot{ }^{37}$ It provides the economy a temporary spell in the $\hat{v}$-region, but the resulting mix of upper and lower class agents (both of which are less numerous) upon reentry into the $\underline{v}$-region may lead to a lower steady state. Figure 5 depicts such a case. The economy beginning at $I$ would have reached steady state $\underline{S S}$, but with the introduction of micro-credit reaches steady state $\underline{S S^{\prime}}$. Economy $\underline{S S}$ has higher output and lower poverty than $\underline{S S^{\prime}}$ and generalized-Lorenz dominates $\underline{S S^{\prime}}$. Thus, micro-credit can worsen an economy in the long run if the self-employment technology that it promotes generates supernormal returns much less frequently than subnormal returns $\left(\pi_{h}^{S} \ll \pi_{l}^{S}\right)$.

\subsection{Dynamics with saver graduation}

Another kind of graduation into the entrepreneurial class may come from saving normal returns rather than achieving supernormal returns. This is impossible given the assumptions on returns and savings rates embodied in the family transitions of Figure 2. In this section, we modify exactly one of these assumptions to guarantee that the savings rate and normal

\footnotetext{
${ }^{37}$ Results from the previous section apply if micro-credit keeps the economy in the $\underline{v}$-region.
} 
returns to self-employment $\left(R_{m}^{S}\right)$ are jointly high enough to allow for eventual graduation into the upper class. This is reflected in Figure 6 as the middle class bequest line crossing the $w^{* *}$ line. ${ }^{38}$ To focus on saver graduation, we eliminate winner graduation: $\pi_{h}^{S}, \pi_{l}^{S}=0$.

The middle class now divides into two subclasses, depending on whether or not one's wealth level is high enough to raise one's descendant to the upper class. We denote the new, intermediate cutoff wealth level $\hat{w},{ }^{39}$ where by assumption $\hat{w} \in\left(w^{*}, w^{* *}\right)$, and the subclasses as the lower middle $\left(P_{t}^{L M}\right)$ and upper middle $\left(P_{t}^{U M}\right)$. For purposes of aggregate dynamics, the wealth distribution becomes a point in the three-dimensional simplex; we treat $P_{t}^{L M}$ as the residual class.

Two of the differential equations describing aggregate dynamics, 1 and 2, need to be modified. Equation 3 is unmodified since the new assumption does not affect the dynamics when $v_{t}=\bar{v}$. When $v_{t}=\underline{v}$, the lower class sees no mobility in or out; thus $\dot{P}_{t}^{L}=0$ and $P_{t}^{L}=P_{0}^{L}$. Further,

$$
\begin{aligned}
\dot{P}_{t}^{U} & =P_{t}^{U M} \\
\dot{P}_{t}^{U M} & =\left(1-P_{t}^{U}-P_{t}^{L}-P_{t}^{U M}\right)-P_{t}^{U M} .
\end{aligned}
$$

The upper class grows due to the bequests of the active upper middle class, $P_{t}^{U M}$. The upper middle class grows due to the bequests of the lower middle class (the term in parentheses) and declines due to its own members graduating to the upper class.

It is clear that the trajectory of an economy in the $\underline{v}$-region is straight upward. The lower class is not changing, while the middle class is gradually moving up to the upper class. The economy ends up on the upper right leg of the $\underline{v}$-region (iff it begins in the shaded area of Figure 7 ) or it transits to the $\hat{v}$-region. ${ }^{40}$

When $v_{t}=\hat{v}$, all active lower class agents exit the lower class. Thus $\dot{P}_{t}^{L}=-P_{t}^{L}$, which

\footnotetext{
${ }^{38}$ Specifically, we now assume $s\left(R_{m}^{S} K^{S}+\rho w^{* *}\right)>w^{* *}$, rather than the reverse. Since $R_{m}^{S} K^{S}=\bar{R}^{S} K^{S}=\hat{v}$, this is equivalent to $s \hat{v} /(1-s \rho)>w^{* *}$.

${ }^{39}$ This cutoff $\hat{w}$ satisfies $s(\hat{v}+\rho \hat{w})=w^{* *}$, that is, equals $\left(w^{* *}-s \hat{v}\right) / s \rho$.

${ }^{40}$ The condition describing the shaded area, that is, for not transitioning to the $\hat{v}$-region, is $P_{0}^{L}>n /(n+1)$.
} 
gives $P_{t}^{L}=P_{0}^{L} e^{-t}$. Further,

$$
\begin{aligned}
\dot{P}_{t}^{U} & =P_{t}^{U M}-\pi_{l}^{E} P_{t}^{U} \\
\dot{P}_{t}^{U M} & =\left(1-P_{t}^{U}-\gamma P_{t}^{L}-P_{t}^{U M}\right)-P_{t}^{U M} .
\end{aligned}
$$

There are two differences between these equations and equations 6. First, there is exit out of the upper class by unlucky entrepreneurs, due to the higher wages. Second, it is not only the lower middle class who move up to the upper middle class, but also some of the lower class; see Figure 6 . We let this fraction be $(1-\gamma) P_{t}^{L}$, so that $\gamma P_{t}^{L}$ reach the lower middle, but not upper middle, class. ${ }^{41}$

Achieving development from the $\hat{v}$-region now appears promising. The lower class vanishes with time. The middle class progresses inevitably upward to the upper class. The only drawback is the unlucky entrepreneurs who are dropping into the (lower) middle class. Now consider the effect of micro-credit. Its main effect will be to move economies destined to remain in the $\underline{v}$-region into the $\hat{v}$-region. If the $\hat{v}$-region is a transitory step en route to development, then micro-credit can be the instrument to bring an economy to full development.

Proposition 2. Under assumption A1 and family dynamics as displayed in Figure 6, if $\pi_{l}^{E}<n / 2$, sufficient availability of micro-credit can bring an underdeveloped (low-wage) economy to full development.

Proof: see Appendix.

Figure 7 displays an economy in the shaded area, $I$, along with its destination without micro-credit $\underline{S S}$ and its path to development with micro-credit. Note that micro-credit is merely a stepping stone en route to full-scale, entrepreneurial development.

This result requires that the leakage out of the upper class, $\pi_{l}^{E}$, not be too large. The intuition comes from the steady state distribution under $\hat{v}$-dynamics. If in steady state the

\footnotetext{
${ }^{41}$ Specifically, define two lower classes, lower lower and upper lower, based on whether agents transit to the lower middle or upper middle class, respectively. Then $\dot{P}_{t}^{L L}=-P_{t}^{L L}$ and thus $P_{t}^{L L}=P_{0}^{L L} e^{-t}$; and similarly for $P_{t}^{U L}$. Since $P_{t}^{L}=P_{0}^{L} e^{-t}$, it is clear that $\gamma=P_{0}^{L L} / P_{0}^{L}$, a constant.
} 
entrepreneurial class is of measure $X$, then $\pi_{l}^{E} X$ will be in the lower middle class and $\pi_{l}^{E} X$ will be in the upper middle class. Thus the entrepreneurial class measures $1 /\left(2 \pi_{l}^{E}+1\right)$. The condition for this to be greater than the critical value $1 /(n+1)$ is that $\pi_{l}^{E}<n / 2$. More generally, if an unlucky entrepreneur spends $k$ periods outside of the upper class before regaining enough assets to graduate, the required condition appears to be $\pi_{l}^{E}<n / k$.

What happens if $\pi_{l}^{E}>n / 2$ ? The $\hat{v}$-region contains an interior steady-state. The algebra needed to examine the solutions to equations 7 appears intractable, but computation shows that under nearly all initial conditions the economy converges to this steady state without exiting into the $\bar{v}$-region. Assessing micro-credit in this case would involve comparing an economy in the $\hat{v}$-region with one in the $\underline{v}$-region, with results similar to that of the previous sections. The point is that saver graduation need not bring development if the rate of attrition in entrepreneurship $\left(\pi_{l}^{E}\right)$ is high relative to the number of generations needed to re-accumulate the required assets.

\section{$5 \quad$ Policy Implications and Conclusions}

Micro-credit in this model reduces poverty in most of the cases we examine. Thus it indeed brings development, if development is defined as positive impact on the lives of the poorest half of the population (as Muhammad Yunus has advocated).

Can micro-credit bring about the more ambitious goal of widespread use of efficient technology, high wages, and equality? This model marks as critical the possibility for saver graduation. That is, the possibility of accumulating normal self-employment returns to reach efficient firm scale is key to long-run development. This possibility depends on two separate quantities, which must jointly be sufficiently high: a) the average return to self-employment activities and b) the savings rate.

Focusing on quantity a) suggests that the productive efficiency of the self-employment undertakings funded by micro-credit institutions is important. This is hardly surprising. It 
suggests that information sharing, technology transfer, and training programs can provide significant value-added in the long run.

Micro-credit institutions are also uniquely positioned to affect quantity b). Financial access of all kinds is costly in many contexts in which they operate, due to geographical distances and due to the small amounts in question. In essence, these difficulties can act as a tax on savings. One can show that the savings rate in the presence of a flat-rate $\operatorname{tax} \tau$ on savings would be $s^{\prime}=s /(1-\tau)$. A micro-credit institution can make use of its employee network, village organizational structures (e.g. groups), and geographical extension to offer savings vehicles cost-effectively. This would lower the 'tax' and raise the effective savings rate $s^{\prime}$, potentially enabling saver graduation. From the point of view of long-run development, micro-lending and facilitating micro-saving thus appear complementary. A combination of both allows for significant graduation into entrepreneurship and eventual raising of the wage. ${ }^{42}$

This model also supports a focus on graduation, which would ideally be incorporated into incentives and evaluation of micro-credit programs. Loan officers should be rewarded not only for number of clients and client longevity in the program, but also for clients who leave the program for formal financial institutions. On the institutional level, programs might be judged in part on the number of their customers that have moved upward from the microcredit sector. The sharing of information between micro-credit and formal credit institutions would be crucial. It would not only enable graduation to be tracked, but would also allow for mitigation of the default incentives of a borrower on the verge of graduation.

As an alternative to graduation between credit institutions, micro-credit institutions may commit to their members indefinitely, providing larger and larger loans and shifting contract terms as needed. It would then be the underlying technological graduation that would be desirable to track and reward. Serving such an array of customers, however, may take most

\footnotetext{
${ }^{42}$ Technically, the model has no room for mobilizing saving since all economic activity takes place in an instant. A richer model would allow for saving from the time entrepreneurial returns are realized until bequest takes place, or from the time returns are realized until a new investment opportunity is learned of.
} 
micro-credit institutions well beyond their core competencies.

However, the model suggests that graduation is not optional, not simply an added benefit of micro-credit. Without significant graduation, micro-credit may lower total income and even raise poverty in the long-run.

The model we analyze provides rich ground for examining various micro-credit scenarios that differ in initial conditions, amount of micro-credit, and so on. As with the original BN model, its potential drawbacks are the simplifying assumptions and focus on special, analytically tractable cases. Though we believe there was and is insight to be gained from these cases, the policy implications should be put in that context. ${ }^{43}$ Future extensions requiring computational analysis may be helpful. Endogenizing the capital and/or labor choices of the self-employed and entrepreneurs, and carrying out simulation with (even roughly) calibrated technology and preference parameters, ${ }^{44}$ would be fruitful avenues.

\section{References}

[1] Christian Ahlin. Corruption and anti-corruption mechanisms under decentralization. Draft, Vanderbilt University, December 2004.

[2] Christian Ahlin and Robert M. Townsend. Selection into and across contracts: Theory and field research. Working Paper, July 2004.

[3] Christian Ahlin and Robert M. Townsend. Using repayment data to test across theories of joint liability lending. Working Paper, February 2005.

[4] Beatriz Armendariz de Aghion and Jonathan J. Morduch. Microfinance beyond group lending. The Economics of Transition, 8(2):401-420, July 2000.

\footnotetext{
${ }^{43}$ Impediments to entrepreneurship beyond credit markets are ignored in our analysis. Among these are lack of human capital or political connections; on the latter, see Ahlin (2004).

${ }^{44}$ Caucutt and Kumar (2005) perform one such exercise using the original BN model.
} 
[5] Beatriz Armendariz de Aghion and Jonathan J. Morduch. The Economics of Microfinance. MIT Press, Cambridge MA, 2005.

[6] Abhijit V. Banerjee, Timothy Besley, and Timothy W. Guinnane. Thy neighbor's keeper: The design of a credit cooperative with theory and a test. Quarterly Journal of Economics, 109(2):491-515, May 1994.

[7] Abhijit V. Banerjee and Andrew F. Newman. Occupational choice and the process of development. Journal of Political Economy, 101(2):274-298, April 1993.

[8] Abhijit V. Banerjee and Andrew F. Newman. Information, the dual economy, and development. Review of Economic Studies, 65(4):631-653, October 1998.

[9] Timothy Besley and Stephen Coate. Group lending, repayment incentives and social collateral. Journal of Development Economics, 46(1):1-18, February 1995.

[10] David Bornstein. The Price of a Dream: The Story of the Grameen Bank. University of Chicago Press, Chicago, 1997.

[11] Elizabeth M. Caucutt and Krishna B. Kumar. Evaluating explanations for stagnation. Working Paper, July 2005.

[12] Maitreesh Ghatak. Group lending, local information and peer selection. Journal of Development Economics, 60(1):27-50, October 1999.

[13] Maitreesh Ghatak. Screening by the company you keep: Joint liability lending and the peer selection effect. Economic Journal, 110(465):601-631, July 2000.

[14] Maitreesh Ghatak and Timothy W. Guinnane. The economics of lending with joint liability: Theory and practice. Journal of Development Economics, 60(1):195-228, October 1999. 
[15] Joseph P. Kaboski and Robert M. Townsend. Policies and impact: An analysis of village-level microfinance institutions. Journal of the European Economic Association, 3(1):1-50, March 2005.

[16] Dean S. Karlan. Social connections and group banking. Yale University Economic Growth Center Discussion Paper No. 913, 2005.

[17] Malgosia Madajewicz. Joint liability versus individual liability in credit contracts. Working Paper, June 2005.

[18] Kiminori Matsuyama. On the rise and fall of class societies. Working Paper, February 2003.

[19] Kiminori Matsuyama. Credit traps and credit cycles. Working Paper, January 2005.

[20] Jonathan Morduch. The microfinance promise. Journal of Economic Literature, 37:1569-1614, December 1999.

[21] Beatrix Paal and Thomas Wiseman. Group lending with endogenous social collateral. Working Paper, 2005.

[22] Ashok S. Rai and Tomas Sjöström. Is Grameen lending efficient? Repayment incentives and insurance in village economies. Review of Economic Studies, 71(1):217-234, January 2004.

[23] Joseph E. Stiglitz. Peer monitoring and credit markets. World Bank Economic Review, 4(3):351-366, September 1990.

[24] Bruce Wydick. Can social cohesion be harnessed to repair market failures? Evidence from group lending in Guatemala. Economic Journal, 109(457):463-475, June 1999. 


\section{A Proofs}

Proof of Proposition 1. Assumption A1 and the family dynamics of Figure 2 give rise to differential equation systems 1-3. An underdeveloped economy by definition begins with $P_{0}^{U}<1 /(n+1)$, and given that micro-credit does not directly affect $P_{0}^{U}$, the economy is described by either system 1 or 2 . Solving the latter gives

$$
P_{t}^{U}=P_{\widehat{S S}}^{U}\left(1-e^{-\left[\pi_{h}^{S}(n+1)+\pi_{l}^{E}\right] t}\right)+P_{0}^{U} e^{-\left[\pi_{h}^{S}(n+1)+\pi_{l}^{E}\right] t}
$$

where $P_{\widehat{S S}}^{U}$ is defined in equation 4. This expression makes clear that (i) if $P_{0}^{U}=P_{\widehat{S S}}^{U}$, then $P_{t}^{U}=P_{0}^{U}$ for all $t \in(0, \infty)$ and (ii) if $P_{0}^{U} \neq P_{\widehat{S S}}^{U}$, then $P_{t}^{U}<\max \left\{P_{\widehat{S S}}^{U}, P_{0}^{U}\right\}$ for all $t \in(0, \infty)$. Since $P_{0}^{U}<1 /(n+1)$ and $P_{\widehat{S S}}^{U} \leq 1 /(n+1)$ (with equality only when $\pi_{l}^{E}=0$ ), we can conclude that $P_{t}^{U}<1 /(n+1)$ for all $t<\infty$.

Consider next dynamics described by system 1 . Inspection gives that both $P_{t}^{U}$ and $P_{t}^{L}$ are increasing, in a fixed ratio $a \equiv \pi_{h}^{S} / \pi_{l}^{S}$. The economy must either transit to the $\hat{v}$-region, where $P_{t}^{U}>P_{t}^{L} / n$, or approach the $P_{t}^{U}+P_{t}^{L}=1$ line from within the $\underline{v}$-region. In the former case, $P_{t}^{U}$ does not reach $1 /(n+1)$, as established in the previous paragraph. In the latter case, $P_{t}^{U}$ approaches $1 /(n+1)$ iff it approaches the single point in the $\underline{v}$-region with $P_{t}^{U}=1 /(n+1)$, that is, $\left(\frac{n}{n+1}, \frac{1}{n+1}\right)$. Even then, it will not reach it in finite time; the solution to system 1 shows $P_{t}^{U}$ strictly monotonically increasing toward its limit:

$$
P_{t}^{U}=P_{0}^{U}+\frac{\pi_{h}^{S}}{\pi_{h}^{S}+\pi_{l}^{S}}\left(1-P_{0}^{U}-P_{0}^{L}\right)\left(1-e^{-\left(\pi_{h}^{S}+\pi_{l}^{S}\right) t}\right)
$$

Thus, $P_{t}^{U}$ will never reach $1 /(n+1)$, that is, the economy will not attain development.

Proof of Proposition 2. Sufficient micro-credit guarantees a wage of $\hat{v}$, since it can lift the entire lower class and thus guarantee that $P_{0}^{L} \leq n P_{0}^{U}$. Assumption A1 and the family dynamics of Figure 6 give rise to the system of equations described by $P_{t}^{L}=P_{0}^{L} e^{-t}$ and 
differential equations 7 , when $v_{t}=\hat{v}$. Solving gives

$$
\begin{aligned}
P_{t}^{U}=P_{S S}^{U}-e^{-\left(1+\pi_{l}^{E} / 2\right) t} & {\left[\delta^{U} \cos (\beta t)+\frac{\delta^{U M}+\left(1-\pi_{l}^{E} / 2\right) \delta^{U}}{\beta} \sin (\beta t)\right] } \\
& \left.-\frac{\gamma P_{0}^{L} e^{-t}}{\pi_{l}^{E}}\left[1-e^{-\pi_{l}^{E} t / 2}\left(\cos (\beta t)+\frac{\pi_{l}^{E}}{2 \beta} \sin (\beta t)\right]\right)\right],
\end{aligned}
$$

where

$$
P_{S S}^{U}=\frac{1}{2 \pi_{l}^{E}+1},
$$

$P_{S S}^{U M}=\pi_{l}^{E} /\left(2 \pi_{l}^{E}+1\right), \delta^{U}=P_{S S}^{U}-P_{0}^{U}, \delta^{U M}=P_{S S}^{U M}-P_{0}^{U M}$, and $\beta=\sqrt{\pi_{l}^{E}\left(4-\pi_{l}^{E}\right)} / 2$. It is clear from equation 8 that $P_{t}^{U}$ approaches $P_{S S}^{U}$ as $t$ gets large. Manipulation of equation 9 gives that $P_{S S}^{U}>1 /(n+1)$ if $\pi_{l}^{E}<n / 2$. This condition then guarantees that under $\hat{v}$ dynamics, $P_{t}^{U}$ will reach the critical value $1 /(n+1)$ in finite time and $\bar{v}$-dynamics will take over. Equation 3 guarantees that when $v_{t}=\bar{v}, P_{t}^{U}$ will monotonically increase toward its steady state value of $\left(n+1-\pi_{l}^{E}\right) /(n+1)$.

It remains to show that the trajectory through the $\hat{v}$-region never crosses into the $\underline{v}$ region; if it did, the dynamics would change and the above analysis would no longer apply. Trajectories in the $\hat{v}$-region satisfy $\dot{P}_{t}^{L}=-P_{t}^{L}$. If $P_{t}^{L}=0$, it is impossible to enter the $\underline{v}$-region, that is, to satisfy $P_{t}^{L}>n P_{t}^{U}$; assume $P_{t}^{L}>0$. Since $P_{t}^{L}$ is declining, to exit the $\hat{v}$ region requires that $\dot{P}_{t}^{U}<0$ and that $\left|\frac{\dot{P}_{t}^{U}}{\dot{P}_{t}^{L}}\right|>1 / n$. Note from equation 7 that $\dot{P}_{t}^{U} \geq-\pi_{l}^{E} P_{t}^{U}$. Combining this with $\dot{P}_{t}^{L}=-P_{t}^{L}$ gives that $\left|\frac{\dot{P}_{t}^{U}}{\dot{P}_{t}^{L}}\right| \leq \pi_{l}^{E} \frac{P_{t}^{U}}{P_{t}^{L}}\left(\right.$ when $\left.\dot{P}_{t}^{U}<0\right)$. Now consider a point in the $\hat{v}$-region near the boundary with the $\underline{v}$-region, the line $P_{t}^{L}=n P_{t}^{U}$. This point can be expressed as $\left(P_{t}^{L}, P_{t}^{U}\right)=(n k, \lambda k)$, where $k \in\left[0, \frac{1}{n+1}\right)$ and $\lambda \in\left(1, \frac{1}{k(n+1)}\right)$. We know that here $\left|\frac{\dot{P}_{t}^{U}}{\dot{P}_{t}^{L}}\right| \leq \pi_{l}^{E} \frac{\lambda}{n}$ (if $\dot{P}_{t}^{U}<0$ ), which is less than $1 / n$ for $\lambda$ satisfying $1<\lambda<1 / \pi_{l}^{E}$. This establishes that economies close to the boundary are not following trajectories that allow for exit from the $\hat{v}$-region into the $\underline{v}$-region; that is, exit downward is impossible. 


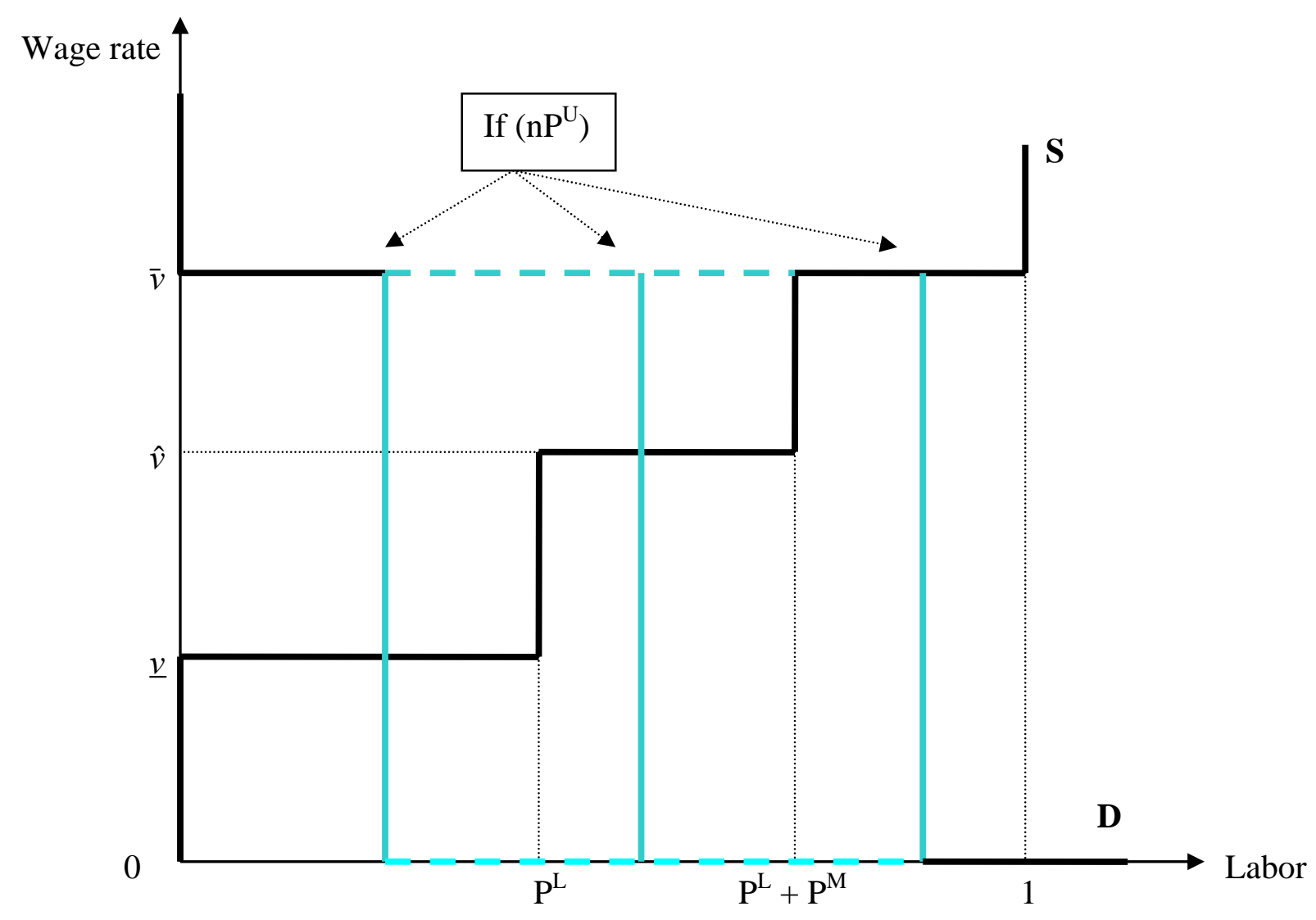

Figure 1: Labor market equilibrium 
When $v_{\mathrm{t}}=\underline{v}$

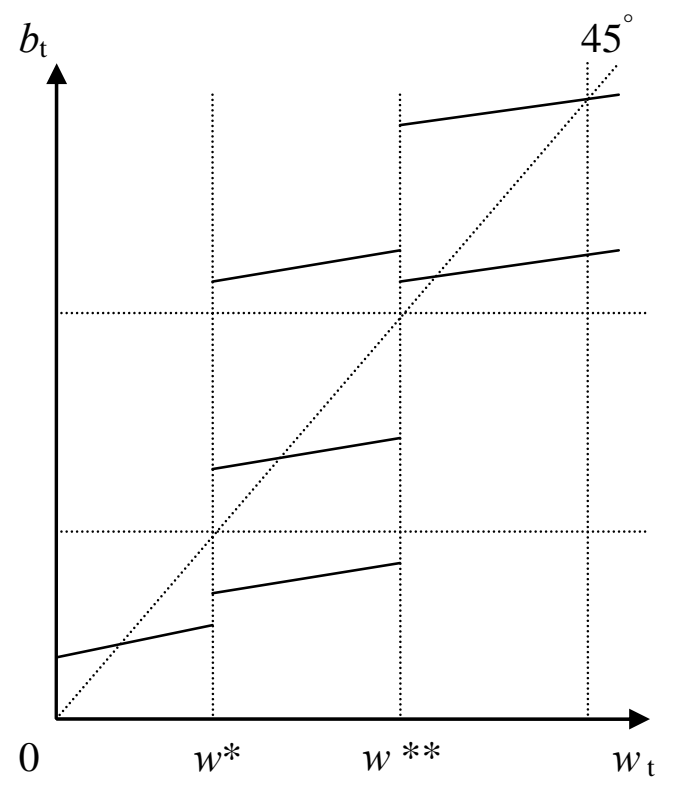

When $v_{\mathrm{t}}=\hat{v}$

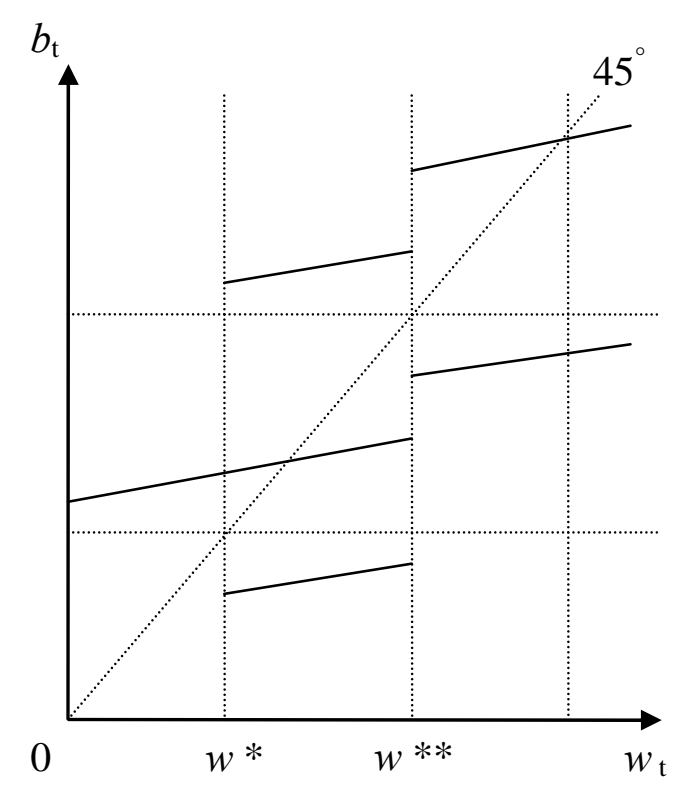

When $v_{\mathrm{t}}=\bar{v}$

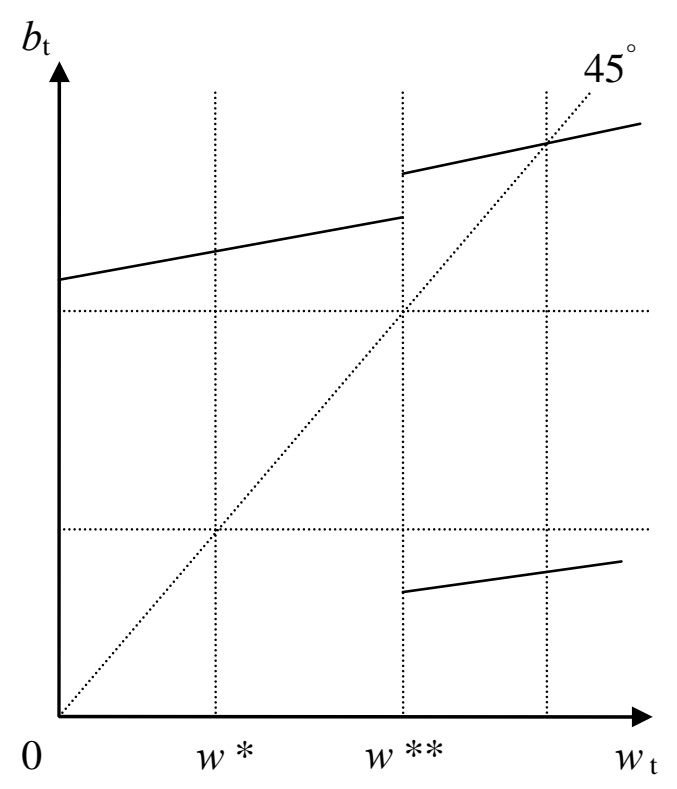

Figure 2: Family wealth transition 


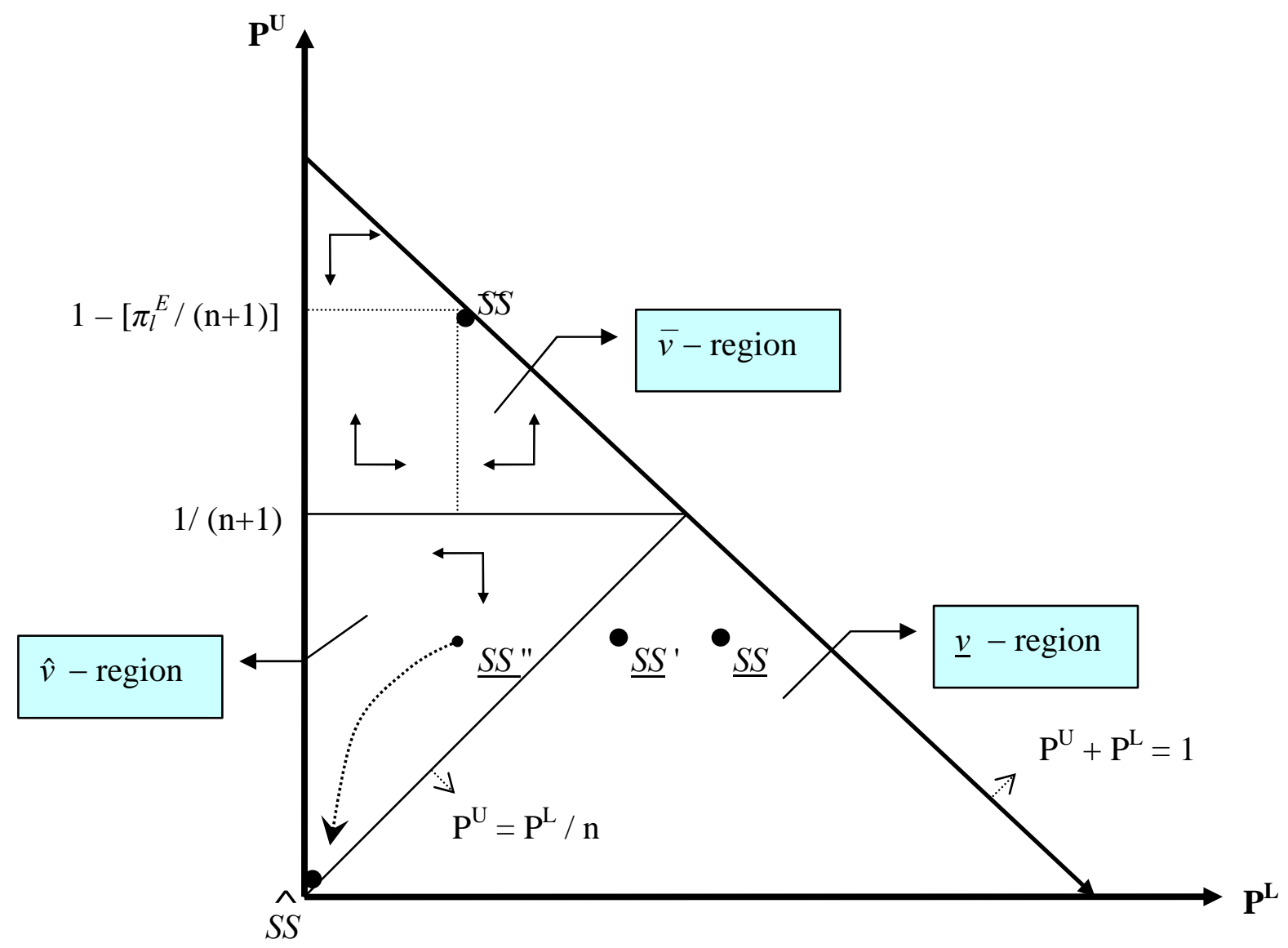

Figure 3: Aggregate wealth dynamics (when $\pi_{l}^{S}, \pi_{h}^{S}=0$ ) 


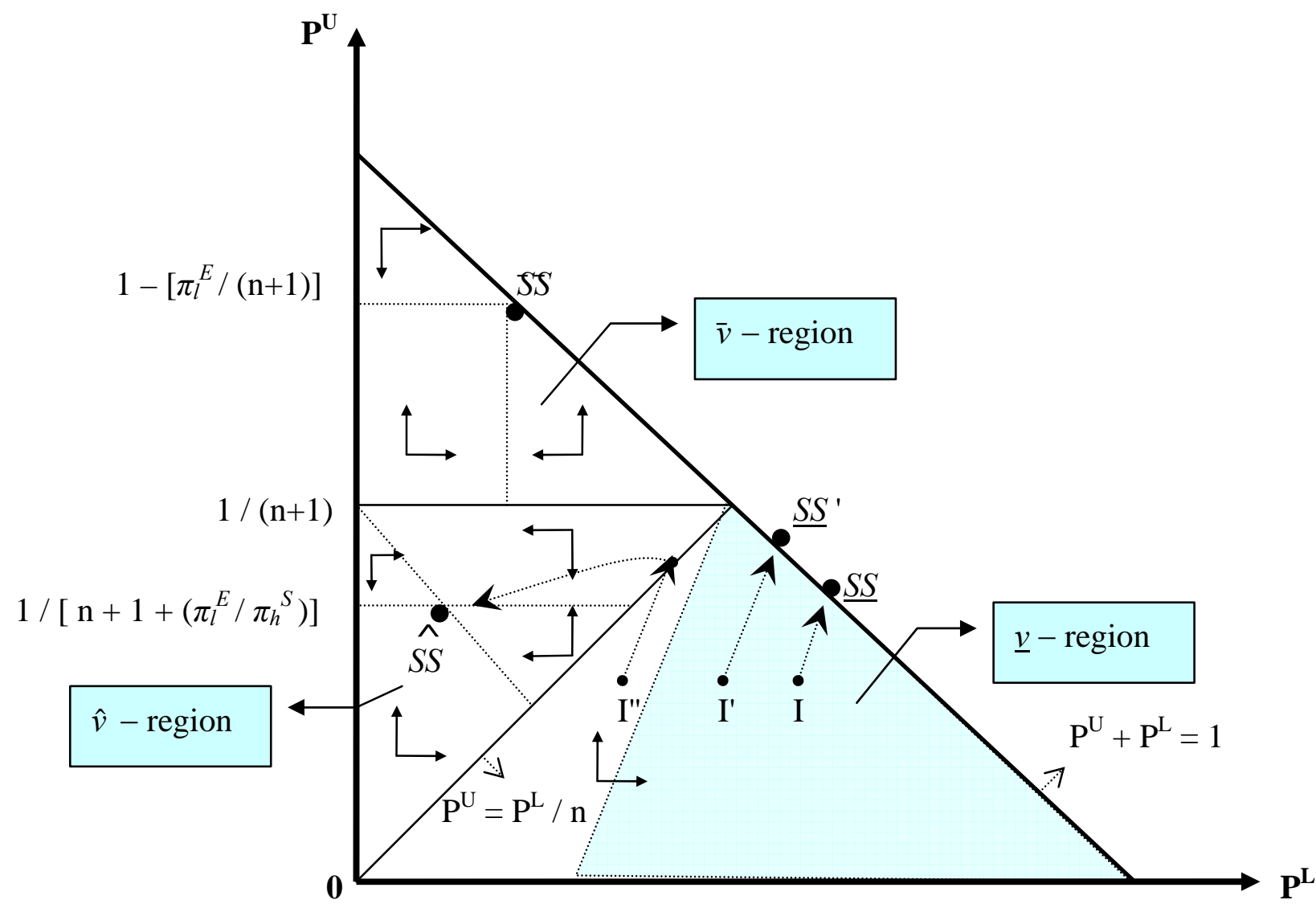

Figure 4: Aggregate wealth dynamics

(when $\pi_{l}^{S}, \pi_{h}^{S} \neq 0$ and $\mathbf{a}>1 / \mathrm{n}$ ) 


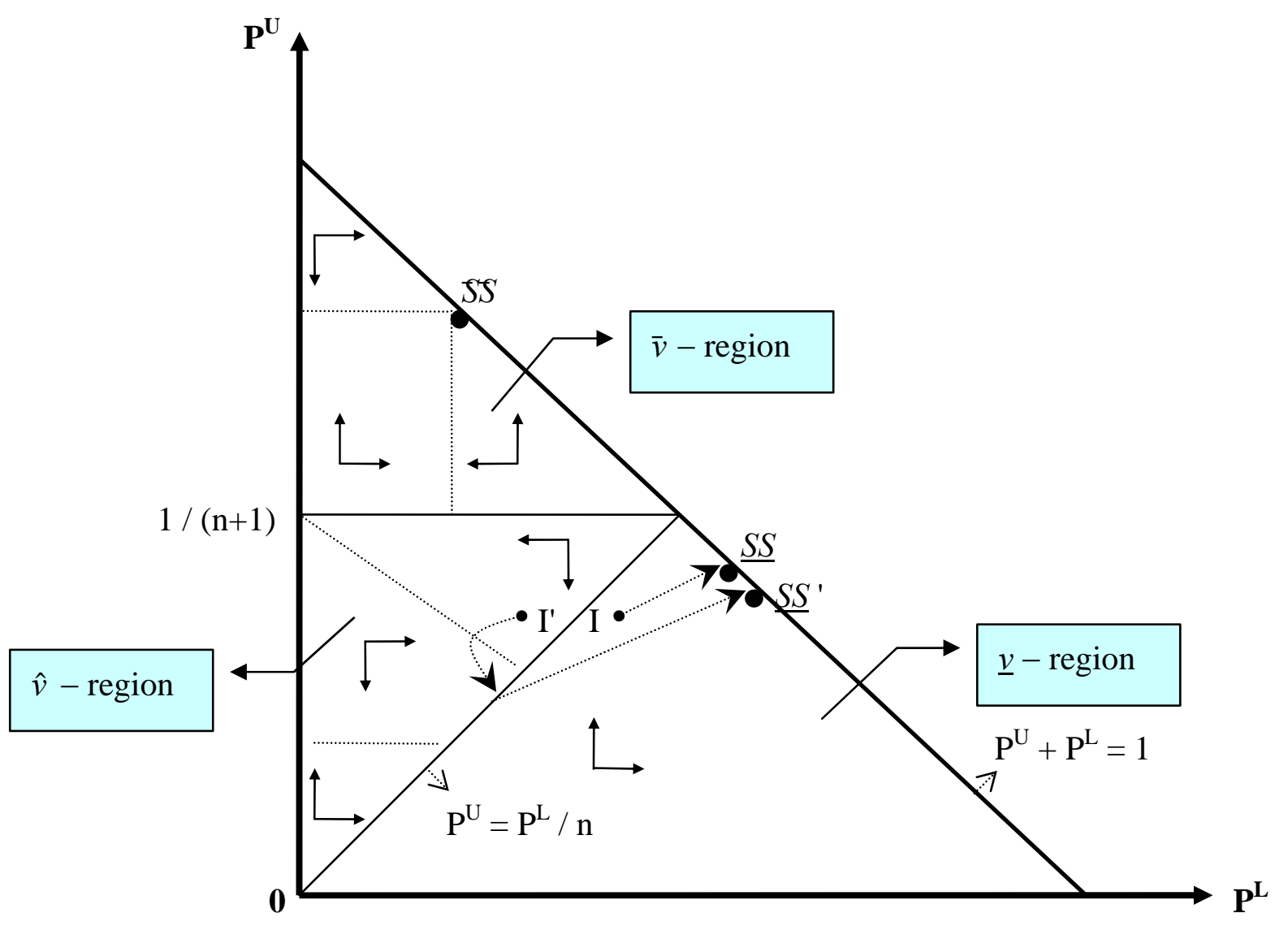

Figure 5: Aggregate wealth dynamics (when $\pi_{l}^{S}, \pi_{h}^{S} \neq 0$ and $\mathbf{a}<\pi_{l}^{E} / \mathrm{n}$ ) 
When $v_{\mathrm{t}}=\underline{v}$

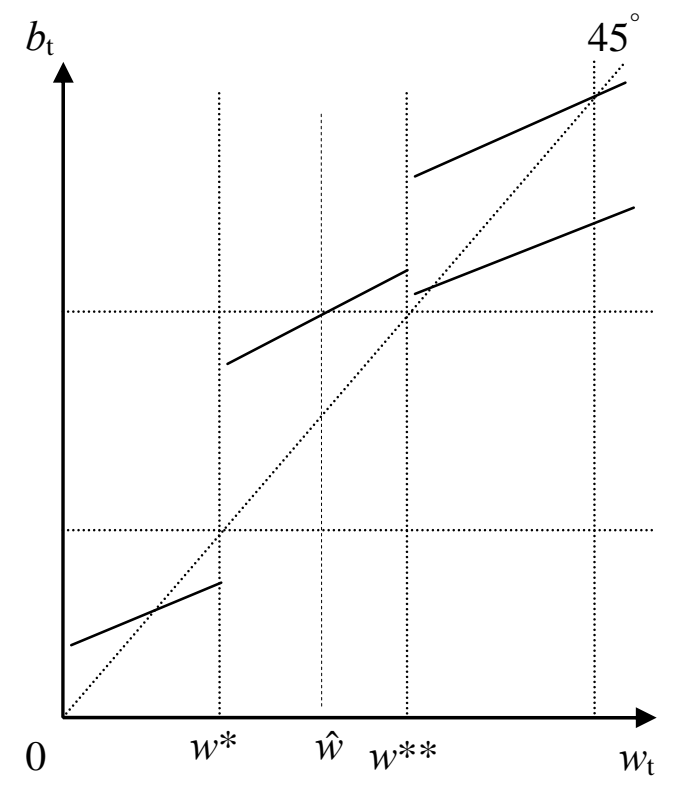

When $v_{\mathrm{t}}=\hat{v}$

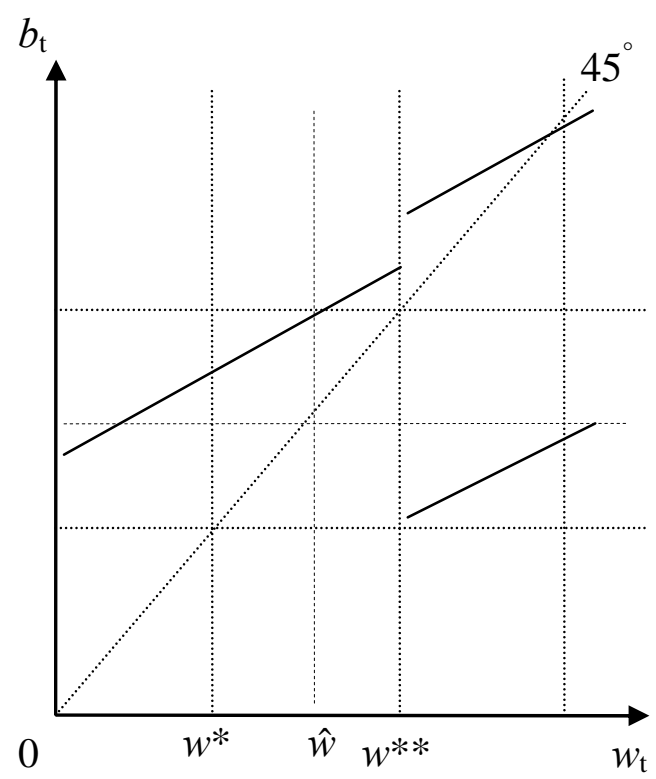

When $v_{\mathrm{t}}=\bar{v}$

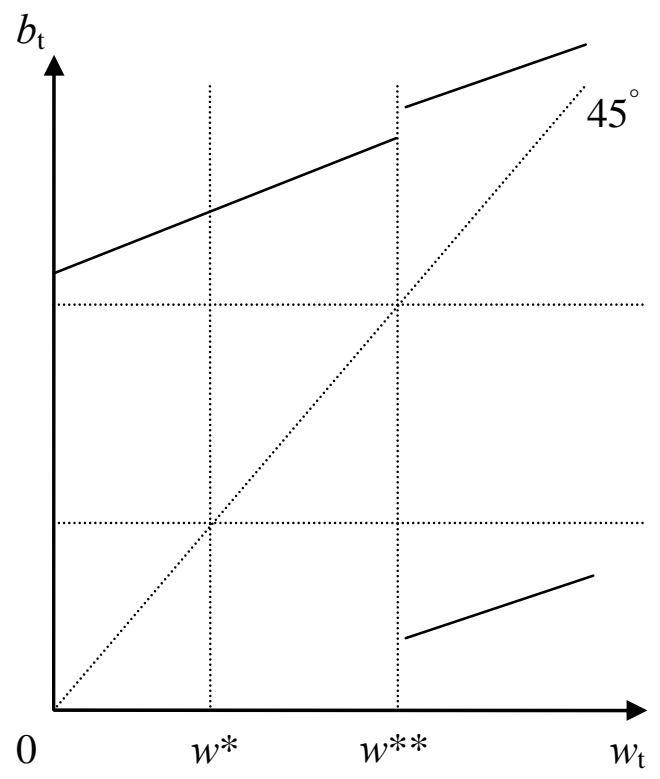

Figure 6: Family wealth transition with saver graduation 


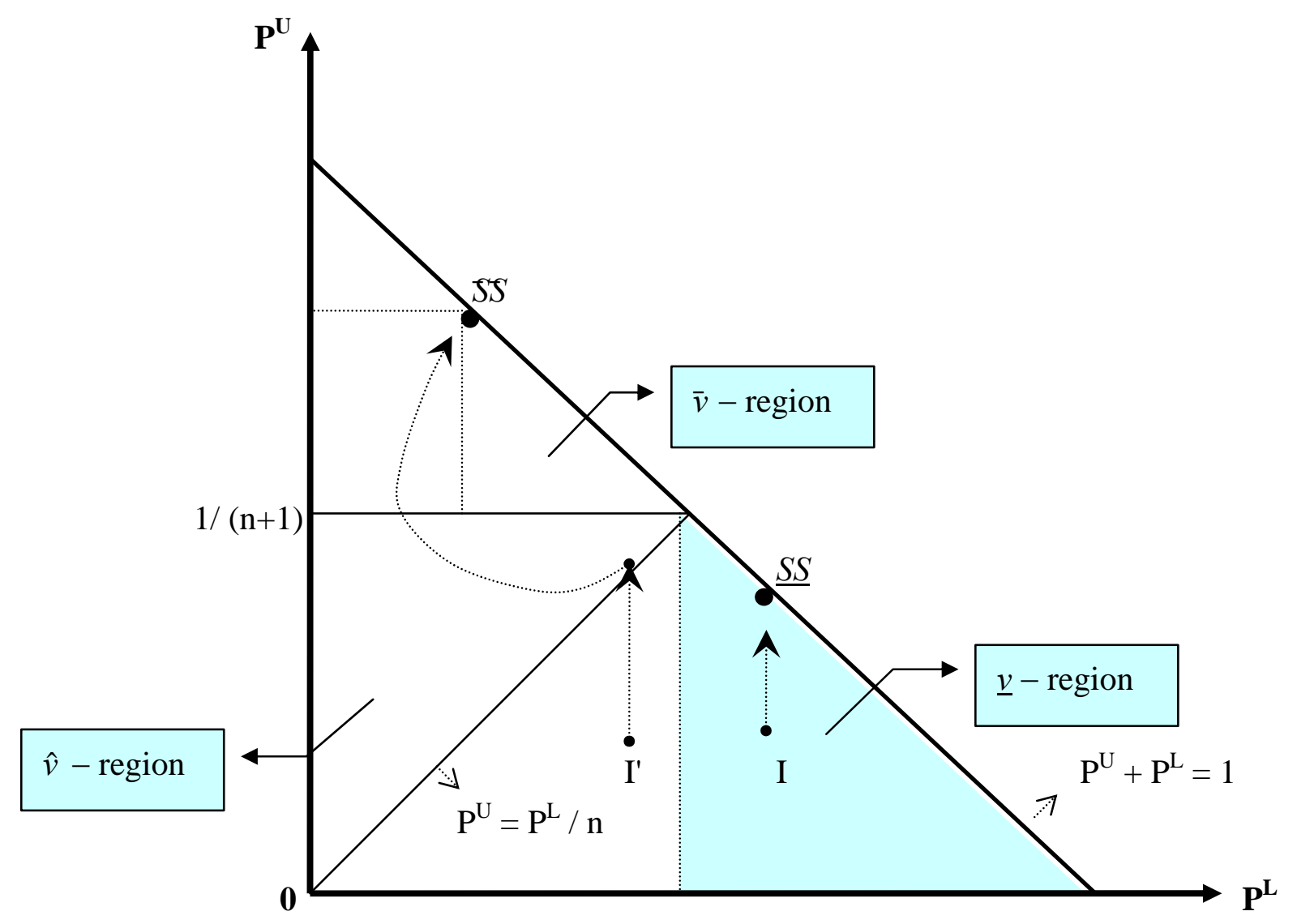

Figure 7: Aggregate wealth dynamics with saver graduation 